Int. J. Plant Sci. 180(2):93-127. 2019. (C) 2018 by The University of Chicago. All rights reserved. This work is licensed under a Creative Commons Attribution-NonCommercial 4.0 International License (CC BY-NC 4.0), which permits non-commercial reuse of the work with attribution. For commercial use, contact journalpermissions@press.uchicago.edu.

1058-5893/2019/18002-0001\$15.00 DOI: $10.1086 / 701319$

\title{
EXTINCT DIVERSITY AMONG EARLY CRETACEOUS ANGIOSPERMS: MESOFOSSIL EVIDENCE OF EARLY MAGNOLIALES FROM PORTUGAL
}

\author{
Else Marie Friis, ${ }^{1, *}$ Peter R. Crane, $\dagger^{\prime} \neq$ and Kaj Raunsgaard Pedersen§ \\ *Department of Palaeobiology, Swedish Museum of Natural History, Stockholm 114 18, Sweden; +Oak Spring Garden Foundation, \\ 1776 Loughborough Lane, Upperville, Virginia 20184, USA; ¥Yale School of Forestry and Environmental Studies, New Haven, \\ Connecticut 06511, USA; and §Department of Geoscience, University of Aarhus, Aarhus DK-8000, Denmark
}

\author{
Editor: Patricia G. Gensel
}

\begin{abstract}
Premise of research. Small angiosperm fossils are diverse in Early Cretaceous mesofossil floras from Portugal and eastern North America. Investigations of these fossils have revealed an unexpectedly high diversity of extinct angiosperms related to lineages that are now species poor, such as Austrobaileyales, Nymphaeales, and Chloranthaceae. Here we analyze Early Cretaceous fruits and seeds from Portugal that are related to eumagnoliid angiosperms and that are also important for understanding extinct diversity in early angiosperms.
\end{abstract}

Methodology. The fossils were prepared by sieving in water; cleaned with $\mathrm{HF}, \mathrm{HCl}$, and water; and studied using scanning electron microscopy and synchrotron radiation X-ray tomographic microscopy. The systematic conclusion based on comparative studies was tested in a phylogenetic analysis.

Pivotal results. We recognize a new group of angiosperms based on fruits and seeds united by features that are otherwise unusual among angiosperms. Two genera, Serialis and Riaselis, are established and 10 species described. Both have unilocular fruiting units formed from a single carpel. Serialis has fruits with two or more seeds, while fruits of Riaselis are always one seeded. In Serialis, seeds are permanently attached to each other and dispersed as a unit. Both genera have anatropous and mesotestal-endotestal seeds with a tiny embryo and a distinctive vasculature in the testa extending from the hilum to the chalaza and then also on the antiraphal side to the micropyle. The fossils are most similar to seeds of Magnoliales but also share some features with seeds of Austrobaileya.

Conclusions. Serialis and Riaselis are the earliest fossils that can be assigned to the Magnoliales but are sufficiently different from those of all Magnoliales that they cannot be assigned to any extant family. Serialis and Riaselis provide further documentation of extensive extinct diversity among early angiosperms, and their abundance in the mesofossil floras suggests that they were common and widespread in early angiosperm communities.

Keywords: early angiosperms, fossil fruits, fossil seeds, perichalazal seeds, postchalazal bundle, Riaselis, Serialis.

\section{Introduction}

The importance of incorporating extinct seed plants into phylogenetic analyses of seed plant evolution has long been recognized because of their potential impact on phylogenetic models of seed plant evolution (Crane 1985). In the case of living angiosperms, however, the rooting of the angiosperm tree and patterns of cladogenesis among early angiosperms are now widely accepted based entirely on molecular data from extant taxa: the potential influence of extinct diversity on our understanding of phylogenetic patterns at this level of angiosperm evolution has so far received little attention.

The discovery of mesofossil floras with numerous wellpreserved angiosperm flowers, fruits, and seeds from the Early Cretaceous continues to provide clear documentation of sig-

${ }^{1}$ Author for correspondence; email: else.marie.friis@nrm.se.

Manuscript received August 2018; revised manuscript received October 2018; electronically published January 4, 2019. nificant extinction among early-diverging angiosperms, and the extent of extinct diversity at this level of angiosperm evolution implies that phylogenetic sampling based solely on extant taxa may be almost as poor for early angiosperms as it is for seed plants (Friis et al. 2018a, 2018b, 2018c, 2018d). In particular, it is increasingly clear that several extant lineages that are crucial to understanding early angiosperm evolution, such as Nymphaeales, Austrobaileyales, and Chloranthaceae, are today species poor and morphologically stereotyped compared to their more diverse extinct Early Cretaceous counterparts (Friis and Pedersen 2011; Friis et al. 2015, 2018a, 2018b, 2018c, 2018d). Even among Laurales, one of the most diverse clades among living eumagnoliid angiosperms, evidence of extensive early extinct diversity is provided by fossil flowers such as Saportanthus E.M.Friis, P.R.Crane \& K.R.Pedersen from the Early Cretaceous of Portugal (Friis et al. 2017) and Potomacanthus Balthazar, K.R.Pedersen, P.R.Crane, Stampan. \& E.M.Friis, Cohongarootonia Balthazar, P.R.Crane, K.R.Pedersen, \& E.M.Friis, Powhatania Balthazar, P.R.Crane, K.R.Pedersen, \& E.M.Friis, 
and Virginianthus E.M.Friis, Eklund, K.R.Pedersen \& P.R.Crane (Friis et al. 1994; von Balthazar et al. 2007, 2011) from the Early Cretaceous of eastern North America.

Other than Laurales, records of eumagnoliids from the Early Cretaceous are scarce. They include pollen of Walkeripollis Doyle, Hotton \& Ward, probably related to Winteraceae (Canellales; Doyle et al. 1990); fruits and pollen of Appomattoxia E.M.Friis, K.R.Pedersen \& P.R.Crane, possibly related to Piperales (Friis et al. 1995); and fossil flowers of Endressinia B.A.R.Mohr \& Bernardes-de-Oliveira that have features resembling Eupomatiaceae and Himantandraceae (Mohr and Bernardes-de-Oliveira 2004). In this study we describe a new complex of fossil fruits and seeds that are abundant in Early Cretaceous mesofossil floras from Portugal and that provide new insights into early eumagnoliid diversity. Ten new species assigned to two new genera, Serialis and Riaselis, are recognized. Both have a combination of characters that place them close to Magnoliales, but they are sufficiently different from those of all living angiosperms that they cannot be assigned to any extant family, and there are also similarities to fruits and seeds of Austrobaileya. These fossils provide further evidence of extinct diversity at an early stage in angiosperm diversification and imply that the six extant families of Magnoliales, and perhaps also Austrobaileyales, are in part relictual and not representative of the morphological diversity that once existed during the early phases of angiosperm diversification.

\section{Material and Methods}

The lignitized and charcoalified fruits and seeds described here are among the most common mesofossils recovered from Portuguese Early Cretaceous mesofloras. More than 3000 specimens have been recovered and studied from exposures at seven different localities in the Lusitanian Basin of western Portugal (Arazede, Buarcos, Catefica, Famalicão, Torres Vedras, Vale de Água, Vila Verde 2). Sediments exposed at the Arazede, Buarcos, Vale de Água, and Vila Verde localities are from the lower part of the Figueira da Foz Formation, which is dated as late Aptian-early Albian (e.g., Dinis et al. 2008, 2010). Sediment samples at Famalicão were collected below the basal conglomerates of the Figureira da Foz Formation and are of late Aptian-early Albian age or older. The Torres Vedras mesofossil flora is from the lower part of the Almargem Formation, which is interpreted as of late Barremian-early Aptian age (Rey 1993; Dinis et al. 2008, 2010). The Catefica mesofossil flora is also from the Almargem Formation and is probably of Aptian age. Samples from Famalicão provided the richest and most diverse of mesofossil assemblages, and these samples also provided most of the charcoalified specimens studied here. A map showing the geographic position of the localities is provided in Friis et al. (2011), together with information on geology and age of these and other Cretaceous plant-bearing deposits in Portugal (see also Friis et al. 2010, 2018a).

The fossils were sieved out of unconsolidated sediments that were disaggregated in water and were then cleaned and rinsed using standard techniques as described in earlier work (e.g., Friis et al. 2011, 2018a). The morphology and internal features of the fossils were studied using a Hitachi Field S-4300 FE-SEM at $2 \mathrm{kV}$ and a Philips SEM 515 at the Swedish Museum of Natural History, Stockholm, and synchrotron radiation X-ray tomographic microscopy (SRXTM) at the TOMCAT Beamline, Swiss
Light Source, Paul Scherrer Institute, Villigen, Switzerland (Stampanoni et al. 2006). For SEM and SRXTM, fossils were attached to metal stubs using a tiny drop of nail polish. Measurements at TOMCAT were performed at $10 \mathrm{keV}$ using a $10 \times$ objective (isotropic pixel size of 0.65 or $0.74 \mu \mathrm{m}$; S153509, S170227S170231, S170242, S171535, S174030, S174095, S174169, S174439, S174480, S174490, S174492, S174813-S174818, S174825, S175129-S175133, S175135, S175136, S175139, S175141，S175145，S175147-S175151，S175157-S175160) and a $20 \times$ objective (isotropic pixel size of $0.325 \mu \mathrm{m}$; S174361, S174362, S174422, S174476-S174479, S174630, S174634, S175168) using a sCMOS detector and various scintillator screens, $17-20 \mu \mathrm{m}$ thick. Analyses of specimens about $1.5 \mathrm{~mm}$ wide or smaller were done over $180^{\circ}$. For larger specimens, a horizontal twofold expansion was used with projections over $360^{\circ}$ (for further information on the method, see Friis et al 2014). Virtual slices and reconstructions of the SRXTM data were made using Avizo software (ver. 9.1.1). Adobe Photoshop CS5 was used to label orthoslices and give an even black background to the SEM images. Two specimens (S105142, S105143) were embedded in 2-hydroxyethyl methacrylate and sectioned using a rotary microtome.

All specimens and raw data from the SRXTM studies are stored at the Swedish Museum of Natural History, Stockholm, Sweden (S). New names of fossil plants are being registered in the Plant Fossil Record Registry, which is hosted and operated by the National Museum Prague for the International Organisation of Palaeobotany, each with a unique Plant Fossil Registry number.

\section{Phylogenetic Analyses}

To test the phylogenetic position inferred for Serialis and Riaselis using comparative morphology and anatomy, we included both genera in a phylogenetic analysis using the morphological matrix of Doyle and Endress $(2010,2014)$ for earlydiverging extant angiosperms. Two characters were added: 143 . Oil cells in testa (0) absent, (1) present; 144. Postchalazal bundle (0) absent, (1) present, unbranched, (2) present, branched. The data set was analyzed by linking the two fossil genera to all branches of a backbone tree of Doyle and Endress (2014). For each position, the tree length was assessed by calculating the number of required character state changes under parsimony using Mesquite version 3.2 (Maddison and Maddison 2017).

Thirty-four morphological characters were scored for the fossils, which are indicated here using the numbers of Doyle and Endress (2014). 81. Pollen unit (0) monads. 82. Pollen size (average) (0) small (>20 $\mu \mathrm{m})$. 83. Pollen shape (1) globose. 87. Infratectum (0) columellar. 88. Tectum (1) perforate (foveolate) to semitectate (reticulate). 89. Grading of reticulum (0) uniform. 90. Striate muri (0) absent. 91. Supratectal spinules (0) absent. 92. Prominent spines (0) absent. 101. Style (0) absent (stigma sessile or capitate). 102. Stigma (0/1) extended or restricted for Serialis, (1) restricted for Riaselis. 109. Short curved appressed unlignified hairs with up to two short basal cells and one long apical cell on carpels $(0)$ absent. 110 . Nectary on dorsal or lateral sides of carpel or pistillode (0) absent. 113. Placentation (0) ventral for Serialis, unknown for Riaselis. 114. Ovule direction (1) horizontal for Serialis, unknown for Riaselis. 115. Ovule curvature $(0)$ anatropous. 116 . Integuments $(0)$ two. 119 . Outer in- 
tegument thickness (at middle of integument length) (0) four and five. 121. Chalaza (0) unextended. 123. Fruit wall (0) wholly or partly fleshy. 124. Lignified endocarp (0) absent. 125. Fruit dehiscence $(0)$ indehiscent. 126. Hooked hairs on fruit (0) absent. 128. Exotesta (0) unspecialized. 129. Mesotesta lignification (1) with sclerotic layer. 130. Mesotesta fleshiness (0) not juicy. 131. Endotesta $(0)$ multiple layer of thin walled cells with fibrous endoreticulum. 132. Tegmen $(0 / 2)$ unspecialized or fibrous to sclerotic for Serialis, (0) unspecialized for Riaselis. 133. Ruminations (0) absent. 134. Operculum (0) absent. 135. Aril (0) absent. 138. Endosperm in mature seed (0) present. 140. Embryo (0) minute. Scoring for the two new characters 143 and 144: 143. Oil cells in testa (0/1) absent or present in Serialis, (0) absent in Riaselis. For extant taxa oil cells were scored as (1) present for Liriodendron, Magnolioideae, and Degeneria and as (0) absent for all other taxa. 144. Postchalazal bundle (1) present. For extant taxa this character was scored as (1) present for Liriodendron, Magnolioideae, Degeneria, Galbulimima, Annonaceae, as (2) present, branched for Myristicaceae, and as (0) absent for all other taxa.

\section{Results}

Descriptions of the Fossils and Taxonomic Treatment

Angiospermae

Order-Magnoliales

Serialis E.M.Friis, P.R.Crane \& K.R.Pedersen gen. nov.

Derivation of generic name. From the arrangement of the seeds in permanent rows (Latin serialis [in rows]).

Generic diagnosis. Fruits/fruitlets indehiscent, with a thin wall and up to about six seeds per carpel, rarely only a single seed. Style lacking. Seeds small, arranged in two rows along the ventral margin, strongly appressed and permanently coherent. Seeds anatropous, bitegmic, and mesotestal-endotestal with thick outer integument (testa) and thin inner integument (tegmen). Exotesta thin. Mesotesta one or two cell layers thick, composed of larger sclerenchyma cells. Endotesta several cell layers thick, composed of small, polygonal, and equiaxial cells with endoreticulate infillings. Seed surface smooth to faintly reticulate or rugulate. Hilum and micropyle close together. Micropyle formed from the inner integument. Micropylar opening in testa wide, transversely oriented. Hilar-micropylar area of adjacent seeds alternating and forming two rows where multiple seeds are present. Ovular vascular bundle continuing beyond the chalaza on the antiraphal side of the seed to the micropyle. Embryo tiny. Endosperm cellular, not-ruminate.

Distinguishing features for the genus. The new genus Serialis is closely similar in fruit and seed features to some extant members of the Magnoliales and to extant Austrobaileya C.T.White, but no living angiosperm has the combination of features as seen in the fossil material. In particular, the coherence of the seeds into permanent units is unique to these fossils. Similar seeds that are permanently coherent in row are known from other Cretaceous strata, but none of these have been described in detail, and none have been formally named (see "Discussion”).
Type species designated here. Serialis antiqua gen. et sp. nov. Plant Fossil Names Registry. PFN000124 (for new genus).

Serialis antiqua E.M.Friis, P.R.Crane \&

K.R.Pedersen gen. et sp. nov. (Figs. 1-3)

Derivation of specific name. From the age of the fossils compared to their living relatives (Latin antiquus [old]).

Specific diagnosis. As for the genus with the following additions: Fruit elongate elliptical to ovate in lateral view. Surface of fruit smooth to faintly wrinkled. Stigma decurrent. Pollen semitectate-reticulate. Seeds four to six. Endotesta and mesotesta of approximately the same thickness. Mesotesta one cell layer thick; cells cubic with thick, undulate anticlinal cell walls; inner surface of anticlinal walls smooth. Endoreticulate infillings of endotesta cells dense. Endotesta without interspersed cavities. Ovular vascular bundle between mesotesta and endotesta. Testa surrounding micropyle not swollen. Outer epidermis of tegmen with slightly elongate, thin-walled cells.

Dimensions. Length of fruit: $1.75-2 \mathrm{~mm}$; width of fruit (dorsiventrally): $1.15 \mathrm{~mm}$.

Holotype designated here. S171535 (Torres Vedras sample 43; illustrated here in figs. $1 A-1 C, 2 A-2 D, 3)$.

Plant Fossil Names Registry. PFN000125 (for new species).

Paratypes designated here. S170079, S174480, S174687 (Torres Vedras sample 43), S100769, S100770 (Torres Vedras sample 44), S175128 (Torres Vedras sample 145).

Repository. Palaeobotanical Collections, Department of Palaeobiology, Swedish Museum of Natural History, Stockholm, Sweden (S).

Type locality. Torres Vedras (NE of Forte de Forca; lat. $39^{\circ} 06^{\prime} 13^{\prime \prime} \mathrm{N}$, long. $\left.09^{\circ} 14^{\prime} 47^{\prime \prime} \mathrm{W}\right)$.

Type stratum and age. Lower part of Almargem Formation; Early Cretaceous (late Barremian-early Aptian).

Occurrence in Portugal. Recorded only from the Torres Vedras locality.

Description and remarks. The species is based on 22 specimens, several of which have a well-preserved fruit wall. Two specimens were studied using SRXTM (S171535, S174480).

The fruits are elongate elliptical to ovate in lateral view and ovate in transverse section (figs. 1, 2A, 2C, 3A). The outer epidermis of the fruit wall is formed by small cells with polygonal and equiaxial facets (fig. 2A, 2B). Small holes in the epidermis indicate the position of scattered trichomes. Trichomes were also observed along the margin of the stigma. Beneath the epidermis the fruit wall consists predominantly of thinwalled parenchyma cells and is several cell layers thick (fig. $3 \mathrm{~A}$, $3 C$ ). The cells are typically collapsed, and the fruit wall may have been fleshy. Larger cavities, probably created by larger cells, are scattered in the fruit wall (fig. $3 A$ ) and may represent the remains of oil cells. The lignitized preservation of the fruit wall does not allow more detailed analysis of the origin of these cavities. The inner epidermis of the fruit wall is formed by narrow, elongate fibers (fig. 3A-3C). Where the fruit wall is abraded, the inner epidermis of the fruit wall typically leaves a striated imprint on the surface of the seed coat (fig. 2E).

The stigmatic area is slightly raised, decurrent, and elongate, up to about $500 \mu \mathrm{m}$ long (fig. $2 A-2 C$ ). Small semitectate-reticulate pollen grains are densely distributed on the stigmatic surface (fig. 2D). The grains are circular in outline, about $19 \mu \mathrm{m}$ in 

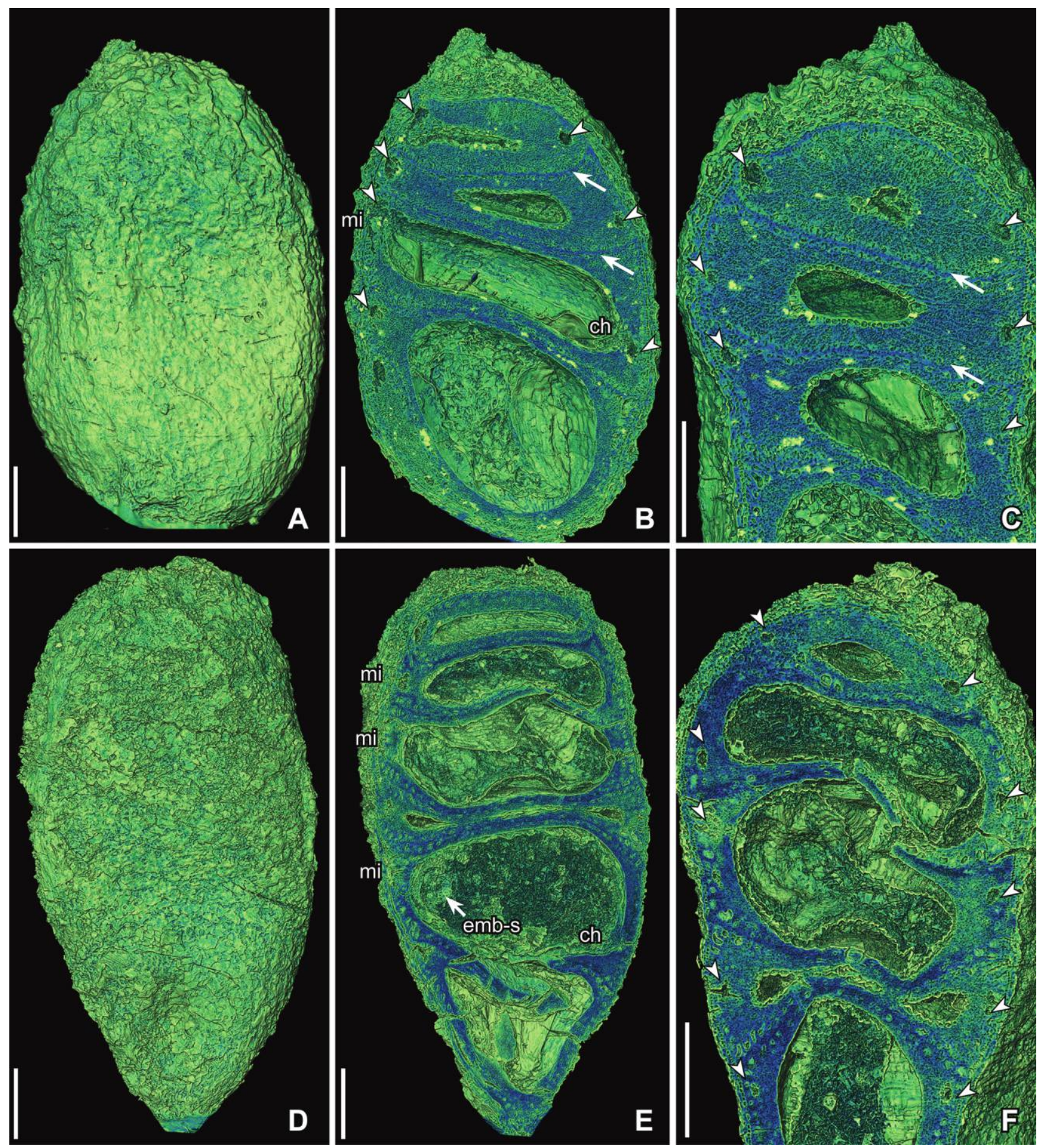

Fig. 1 Synchrotron radiation X-ray tomographic microscopy images (volume renderings) of fruits of Serialis antiqua gen. et sp. nov. from the Early Cretaceous Torres Vedras locality, Portugal (sample Torres Vedras 43), showing thin-walled, indehiscent fruits and closely coherent seeds with micropyles (mi) and chalazas (ch) opposite each other. Note ovular vascular bundles (arrowheads) that extend on both the raphal and antiraphal sides of the seed and the narrow contact region between coherent seeds (arrows). A-C, Holotype, S171535. A, Lateral view of fruit with four seeds showing apical stigmatic region. $B, C$, Longitudinal sections in the dorsiventral plane (B, cut at orthoslice yz0669) and longitudinal section perpendicular to the dorsiventral plane (C, cut at orthoslice xz0863) showing four coherent seeds. $D-F, S 174480$; fruit with six seeds in lateral view $(D)$ and two longitudinal sections, one in the dorsiventral plane ( $E$, cut at orthoslice yz0907) and one perpendicular to the dorsiventral plane ( $F$, cut at orthoslice yz0907) showing uneven development of the individual seeds and empty space from embryo (emb-s). Scale bars $=250 \mu \mathrm{m}$. 

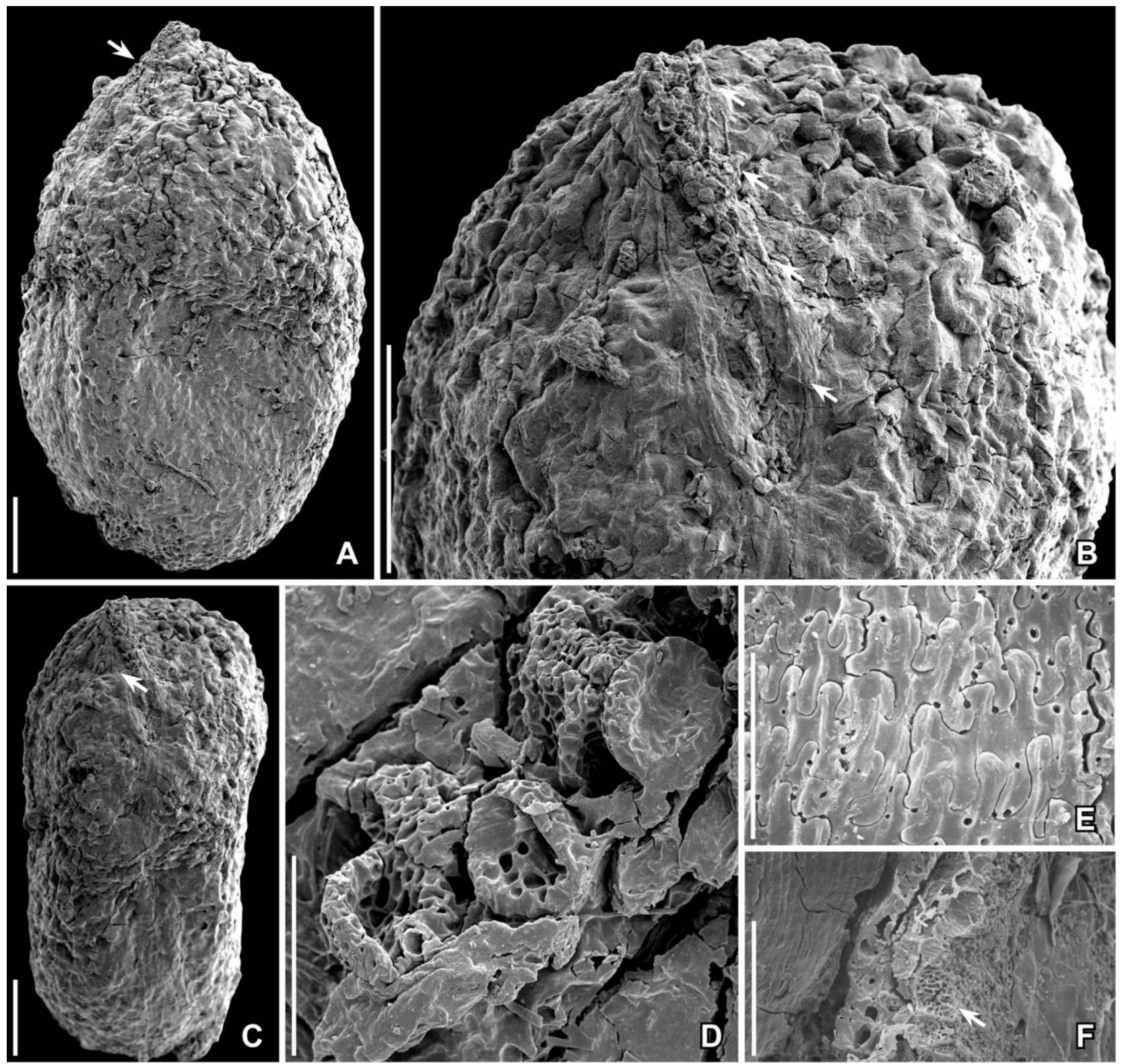

Fig. 2 SEM images of fruits of Serialis antiqua gen. et sp. nov. from the Early Cretaceous Torres Vedras locality, Portugal, showing thinwalled fruit wall and decurrent stigmatic region (arrows) with adhering pollen grains and details of seed coat. A-D, Holotype, S171535 (sample Torres Vedras 43); oblique dorsiventral view $(A)$ and ventral view $(B, C)$ of fruit showing stigmatic area with adhering pollen grains $(D)$. E, S100769 (sample Torres Vedras 44); detail of outer surface of mesotesta cells showing small pits irregularly spaced on the periclinal walls but mainly following the sinuous outlines of the anticlinal walls. F, S100770 (sample Torres Vedras 44), details of the seed coat showing the fibrous sclerified endoreticulate infillings of the endotesta cells (arrow). Scale bars $=250 \mu \mathrm{m}(A-C), 25 \mu \mathrm{m}(D), 50 \mu \mathrm{m}(E), 125 \mu \mathrm{m}(F)$.

diameter, and apparently monocolpate. All grains on the stigmatic surface are of the same kind. A single Ginkgo-type pollen grain was found on the fruit surface next to the stigmatic area.

Each fruit contains four to six seeds arranged in two rows along each side of the ventral suture. The seeds are permanently attached together as a single unit. Seeds of the same unit are typically of different sizes, indicating that not all seeds developed to maturity (figs. $1 B, 1 C, 1 E, 1 F, 3 D$ ). Seeds are anatropous and bitegmic, with the micropyle and hilum close together. The mi- cropyle is formed from the inner integument. There is no exotestal or mesotestal tissue between the micropyle and the hilum. In rare specimens where the fruit wall is abraded, the micropylarhilar opening in the testa is seen as a transversely aligned ellipsoidal or drop-shaped slit.

The ovular vascular bundle is well preserved in parts of the seeds but is typically degraded and is seen as a hollow canal between the endotesta and the mesotesta (figs. $1 B, 1 C, 1 F, 3 C$, $3 E)$. It extends from the hilum, close to the micropyle, to the 

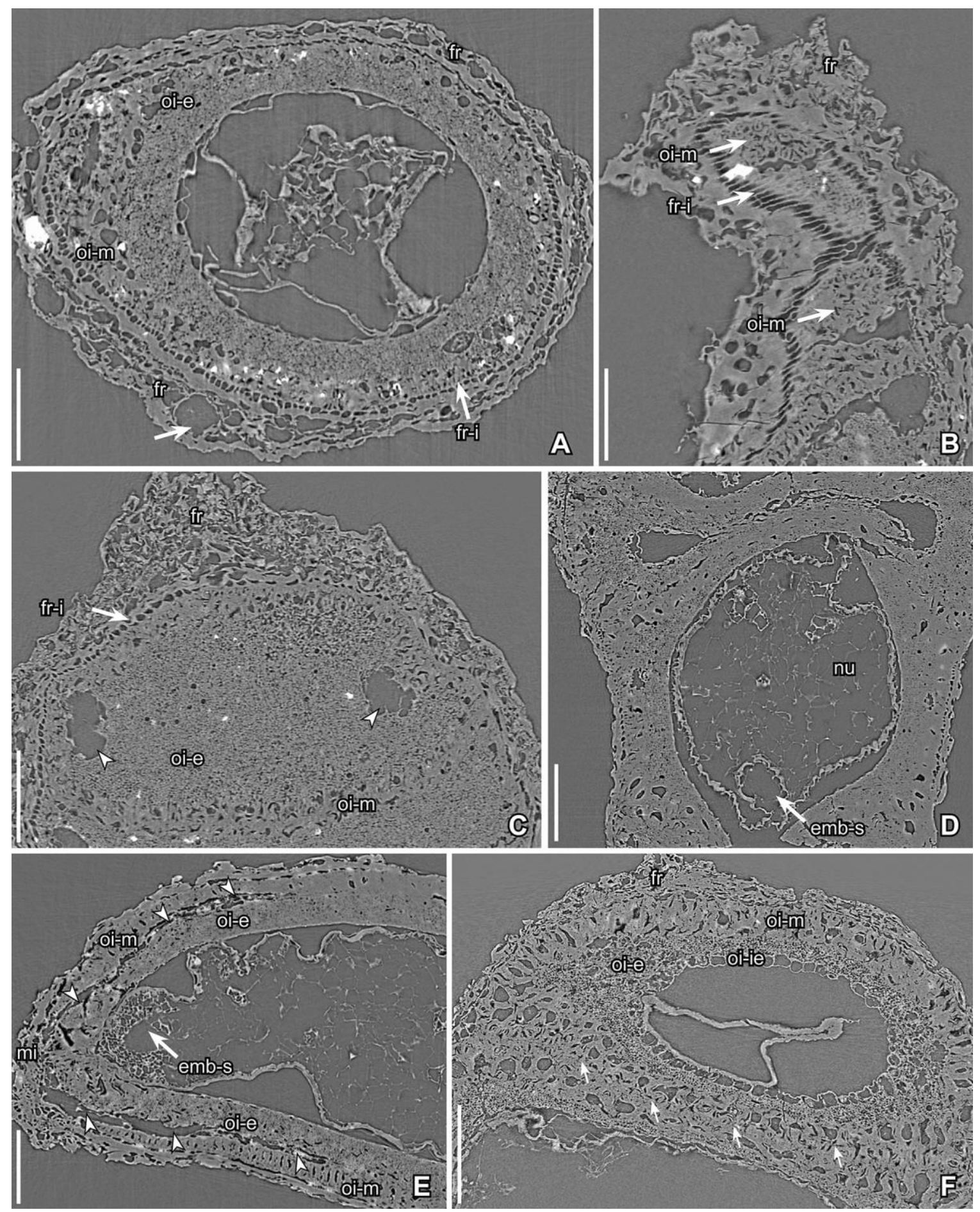

Fig. 3 Synchrotron radiation X-ray tomographic microscopy images (orthoslices) of a fruit and seeds of Serialis antiqua gen. et sp. nov. from the Early Cretaceous Torres Vedras locality, Portugal (sample Torres Vedras 43), showing fruit wall (fr) with the inner epidermis of narrow, elongate cells (fr-i), thick seed coat consisting mainly of the mesotesta (oi-m) and endotesta (oi-e), and, in $D-F$, nutritive tissue (nu) surrounding an empty space created by the tiny embryo (emb-s). A-C, Holotype, S171535. A, Transverse orthoslice (xy2256) of fruit showing the fruit wall containing probable oil cells (arrow), cells of the inner epidermis of the fruit wall with small square cell outlines, the well-developed mesotesta composed of cells with thick walls and large irregular lumens, and the massive endotesta. B, Longitudinal (tangential) orthoslice (yz0174) through part of the fruit wall and the outer part of the seed coat showing the structureless tissue of the fruit wall, the elongated outlines of the narrow cells of the inner epidermis of the fruit wall, and the cells of the mesotesta with thick, partly undulate cell walls. C, Longitudinal (tangential) orthoslice (yz0941) showing the structureless tissue of the fruit wall, the square outlines of the narrow, elongate cells that comprise the inner epidermis of the fruit wall, the cells of the mesotesta with thick cell walls, and the massive endotesta composed of cells in which the lumen is almost completely filled with fibrous sclerified material; note cavities from ovular vascular bundles (arrowheads). D, E, S174488. D, Longitudinal orthoslice (yz0683) of seed showing the mesotesta and the massive endotesta around the seed cavity, which contains the nutritive tissue 
chalaza at the other end of the seed, and then continues on the antiraphal side of the seed from the chalaza to the level of the micropyle. The bundle on both the raphal and antiraphal sides of the seed appears to be equally well developed (fig. $3 E$ ).

The testa is thick, mesotestal-endotestal, with the mesotesta and the endotesta of approximately the same thickness over most of the seed (fig. $3 A, 3 E, 3 F$ ). In the zone between two adjacent seeds, both the mesotesta and the endotesta are thinner than in other parts of the seed (figs. $1 B, 1 E, 1 F, 3 D, 3 F$ ). The mesotesta is one cell layer thick and consists of almost cubic sclerenchyma cells. The cell walls are thick, with scattered perforations; the anticlinal walls are of almost equal thickness from inside to outside and are strongly folded near their inner and outer surfaces, creating undulate-stellate facets on both the inner and outer surfaces of the mesotesta (figs. $2 E, 3 B$ ). The endotesta is several cell layers thick and composed of small polygonal and equiaxial cells with endoreticulate infillings and a small central angular cavity (figs. $2 F, 3 A, 3 C, 3 F$ ). The inner epidermis of the testa consists of thin-walled, slightly elongate cells (fig. $3 F$ ). The tegmen is thin, with slightly elongate cells of the outer epidermis that radiate from the chalaza to the micropyle. The surface of the seed cavity is smooth (figs. $1 B, 1 C, 1 E, 1 F, 3 A, 3 D, 3 E$ ).

Nutritive tissue was observed in specimen S174488 (fig. 3D, $3 E$ ). It is cellular, composed of small, thin-walled, polygonal, and equiaxial cells. A small empty space at the micropylar end of the nutritive tissue indicates the original position and size of the tiny embryo (fig. 3D, 3E).

\section{Serialis parva E.M.Friis, P.R.Crane \& K.R.Pedersen sp. nov. (Figs. 4, 5)}

Derivation of specific name. From the small size of the seeds (Latin parvus [small]).

Specific diagnosis. As for the genus with the following additions: Fruit elongate elliptical to ovate in lateral view. Surface of fruit faintly reticulate. Stigma restricted. Seeds two, rarely one. Mesotesta slightly thicker than endotesta. Mesotesta one cell layer thick; cells tall, cubic to palisade shaped; cell walls unevenly thickened and anticlinal walls undulate; inner surface of anticlinal walls smooth. Endoreticulate infillings of endotesta cells dense. Endotesta without interspersed cavities. Ovular vascular bundle between mesotesta and endotesta. Testa surrounding micropyle not swollen. Outer epidermis of tegmen with slightly elongate, thin-walled cells.

Dimensions. Length of fruit: $0.75-1.08 \mathrm{~mm}$; width of fruit (dorsiventrally): $0.65-0.7 \mathrm{~mm}$.

Holotype designated here. S174479 (Torres Vedras sample 43; illustrated here in figs. 4A-4C, 5A).

Plant Fossil Names Registry. PFN000126 (for new species).

Paratypes designated here. S174476, S174477, S174478, S174686 (29 specimens), S174991 (18 specimens; Torres Vedras sample 43), S174630, S174634 (Torres Vedras sample 298).

Other material. S175168 (Buarcos sample 211).
Repository. Palaeobotanical Collections, Department of Palaeobiology, Swedish Museum of Natural History, Stockholm, Sweden (S).

Type locality. Torres Vedras (NE of Forte de Forca; lat. $39^{\circ} 06^{\prime} 13^{\prime \prime} \mathrm{N}$, long. $\left.09^{\circ} 14^{\prime} 47^{\prime \prime} \mathrm{W}\right)$.

Type stratum and age. Lower part of Almargem Formation; Early Cretaceous (late Barremian-early Aptian).

Occurrence in Portugal. Most of the specimens are from the Torres Vedras locality; a single specimen is also recorded from the Buarcos locality.

Description and remarks. The species is based on 53 specimens, most with remains of fruit wall preserved. Six specimens were studied using SRXTM (S174476-S174479, S174630, S174634).

The fruits are elliptical to ovate in lateral view and ovate in transverse section with a slightly reticulate outer surface (figs. $4 A-4 E, 5 A, 5 B$ ). The fruit wall is generally poorly preserved, and the cells are typically collapsed (fig. 5B, 5C). Oil cells, or cavities potentially created by oil cells, have not been observed. The outlines of cells of the outer epidermis are not clear, but the cells of the inner epidermis are better preserved. They are narrowly elongate and leave a finely striate pattern on the outer surface of the seeds (fig. $4 A, 4 B$ ). The stigmatic area is restricted and slightly raised (fig. 4). No pollen grains were observed on the stigma or fruit surface.

Each fruit contains two seeds or more rarely a single seed (figs. 4A-4E, 5A). In two-seeded fruits, the seeds are strongly attached in permanent units, and both seeds appear to be mature (figs. $4 C, 5 A$ ). Seeds are similar in general organization to the type species (fig. $4 F, 4 H$ ). The micropylar opening in the testa is not exposed in any of the specimens.

The ovular vascular bundle is seen as a hollow canal between the endotesta and the mesotesta (figs. $4 F, 5 B$ ). The bundle on both the raphal and antiraphal sides of the seed appears to be equally well developed.

The testa is thick, mesotestal-endotestal, with the mesotesta slightly thicker than the endotesta (fig. $5 A, 5 B$ ). The mesotesta is one cell layer thick, consisting of almost cubic sclerenchyma cells with evenly thickened walls (fig. $5 A, 5 B$ ). The walls appear to be slightly folded toward the outside and inside, but this feature is not obvious in the specimens studied using SRXTM. The endotesta is several cell layers thick, composed of small polygonal and equiaxial cells with endoreticulate infillings and a small rounded or angular central cavity that is interpreted as the imprint of a single crystal (fig. 5C). The inner epidermis of the testa was not observed. The tegmen is thin, with thin-walled, slightly elongate cells radiating from the chalaza to the micropyle (fig. 4E, 4H). The surface of the seed cavity is smooth (fig. 5B).

Nutritive tissue observed in specimen S174478 (figs. 4F, $5 D$ ) is cellular and composed of small, thin-walled, polygonal, and equiaxial cells. The original position of the embryo is indicated by a small empty space at the micropylar end of the nutritive tissue (figs. $4 F, 5 B$ ).

and a cavity indicating the former position of the embryo. E, Transverse orthoslice (xy1755) of seed showing the mesotesta and the massive endotesta around the seed cavity, which contains the nutritive tissue and a cavity indicating the former position of the embryo; note the course of the ovular vascular bundle (arrowheads) between the mesotesta and the endotesta on both sides of the micropylar-hilar region (mi). F, Longitudinal orthoslice (yz1019) showing the structureless tissue of the fruit wall, the cells of the mesotesta with thick cell walls, and the endotesta around the seed cavity; note the prominent inner epidermis of the endotesta surrounding the seed cavity; note the contact zone between the two seeds (arrows), S174479. Scale bars $=125 \mu \mathrm{m}(A-C, E, F), 250 \mu \mathrm{m}(D)$. 

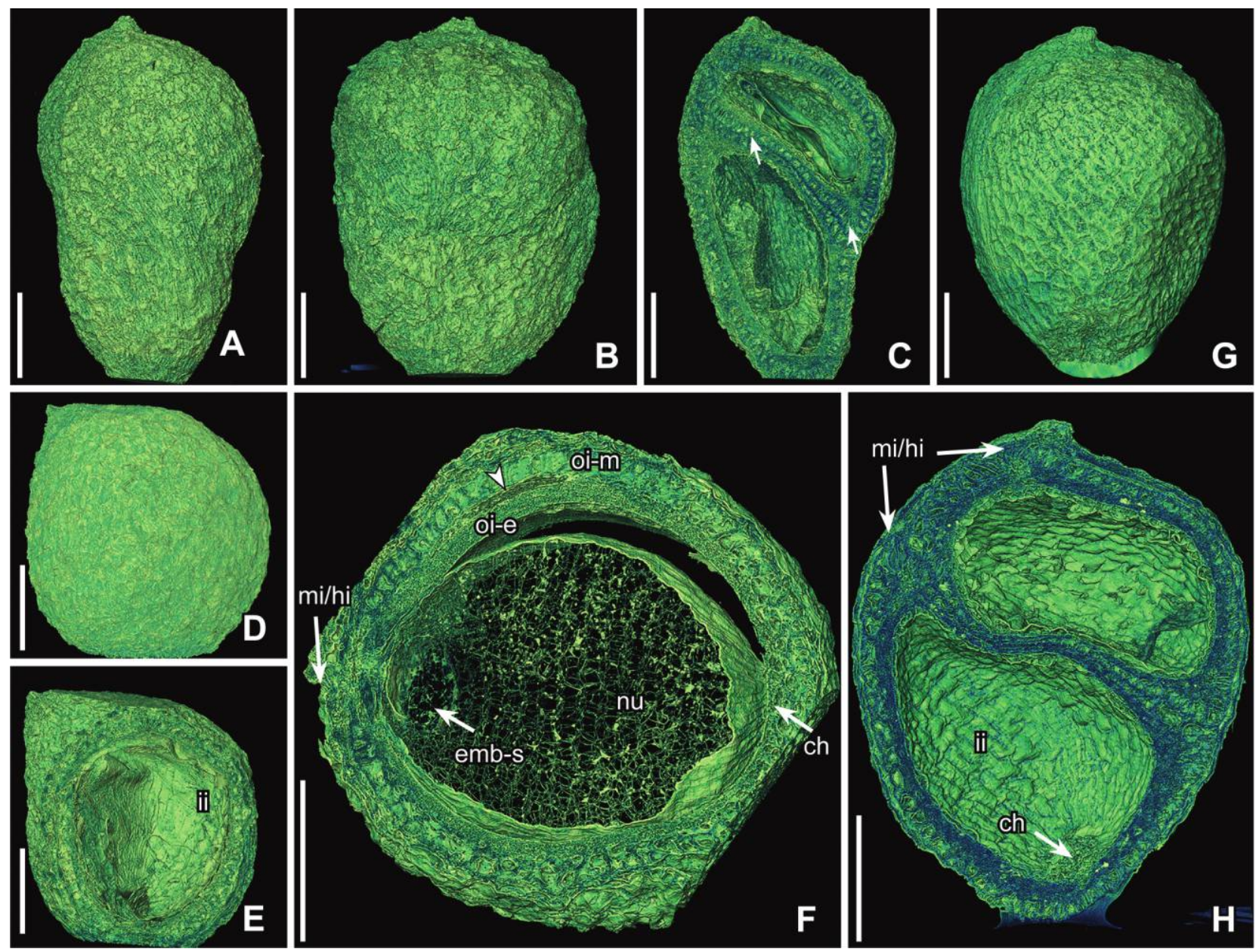

Fig. 4 Synchrotron radiation X-ray tomographic microscopy images (volume renderings) of fruits and seeds of Serialis parva sp. nov. from the Early Cretaceous of Portugal showing thin-walled, indehiscent fruits with one or two seeds. A-C, Holotype, S174479 (sample Torres Vedras 43). $A, B$, Lateral $(A)$ and ventral $(B)$ view of fruit showing apical stigmatic region and striated surface. $C$, Longitudinal section parallel to the dorsiventral plane showing two seeds (cut at orthoslice xz0953). D, E, S174476 (sample Torres Vedras 43); lateral view $(D)$ and cut longitudinal section (E, cut at orthoslice yz0681) of fruit with a single seed showing the apical stigmatic region, weakly reticulate surface, and thin-walled, slightly elongate cells of the tegmen (ii). F, S174478 (sample Torres Vedras 43); transverse section of seed (cut between orthoslices yz0820 and yz0820) showing the inflated cells of the mesotesta (oi-m) and the heavily sclerified cells of the endotesta (oi-e); note the nutritive tissue (nu) at the center of the seed (presumed endosperm) and an empty cavity from the embryo (emb-s) adjacent to the micropyle and the hilum (mi/hi) and opposite the chalaza (ch); note the course of the ovular vascular tissue between the mesotesta and the endotesta (arrowhead). G, H, S175168, (sample Buarcos 211). G, Lateral view of fruit with two closely coherent seeds; note restricted apical stigma. $H$, Cut longitudinal section parallel to the dorsiventral plane (cut at orthoslice yz0945) showing two closely coherent seeds with micropyles and hila (mi/hi) toward the ventral surface and the chalaza (ch) opposite the micropyle; note slightly elongate cells of the thin tegmen (ii). Scale bars $=250 \mu \mathrm{m}$.

\section{Serialis elongata E.M.Friis, P.R.Crane \& K.R.Pedersen sp. nov. (Figs. 6, 7)}

Derivation of specific name. From the elongate cells of mesotesta (Latin elongatus [elongate]).

Specific diagnosis. As for the genus with the following additions: Fruit elongate elliptical to ovate in lateral view. Surface of fruit irregular. Stigma restricted. Seeds two. Mesotesta thicker than endotesta. Mesotesta one cell layer thick; cells tall, palisade shaped with anticlinal cell walls thickened toward the inside of the seed and thin toward the outside; anticlinal walls slightly undulate toward the outer surface of mesotesta; inner surface of anticlinal walls smooth. Endoreticulate infillings of endotesta cells dense. Endotesta without interspersed cavities. Ovular vascular bundle in endotesta. Testa surrounding micropyle not swollen. Outer epidermis of tegmen with narrow, elongate, thin-walled cells.

Dimensions. Length of fruit: $1.42-2 \mathrm{~mm}$; width of fruit (dorsiventrally): 0.98-1.37 mm.

Holotype designated here. S174169 (Vale de Água 408; illustrated here in figs. 6A-6C, 7A, 7C).

Plant Fossil Names Registry. PFN000127 (for new species).

Paratypes designated here. S175159 (Vale de Água sample 19), S175160 (Vale de Água sample 329), S175139 (Vale de Água sample 383), S175141 (Vale de Água sample 408). 

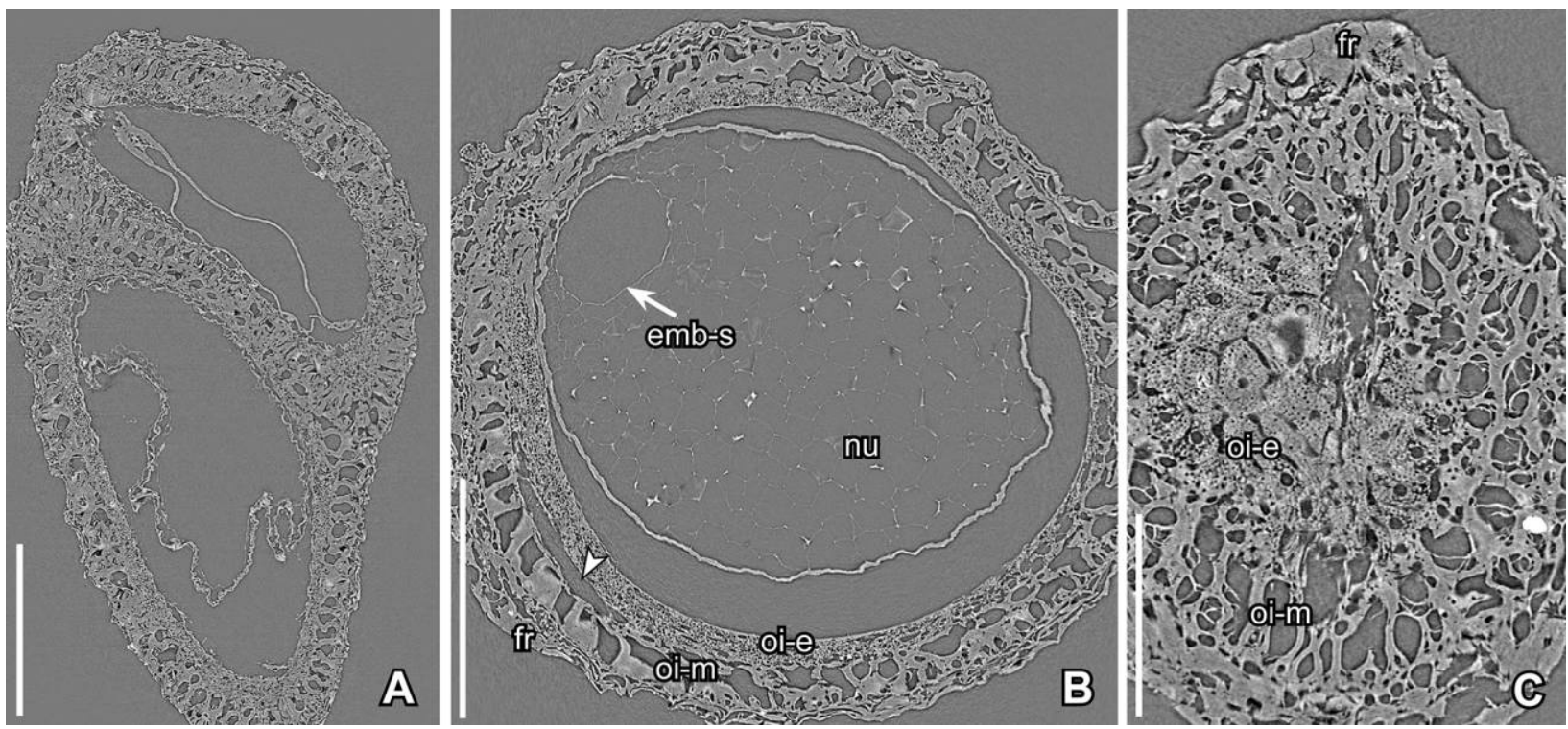

Fig. 5 Synchrotron radiation X-ray tomographic microscopy images (orthoslices) of fruits and seeds of Serialis parva sp. nov. from the Torres Vedras locality, Portugal (sample Torres Vedras 43). A, Holotype, S174479; longitudinal orthoslice (xz0914) of thin-walled, indehiscent fruit parallel to the dorsiventral plane showing two closely coherent seeds with prominent cells of the mesotesta with large lumens and thick walls. B, S174478; transverse section (orthoslice yz0835) of an indehiscent fruit showing the thin fruit wall (fr) and seed with well-developed mesotesta (oi-m) and endotesta (oi-e); note delicate remains of nutritive tissue (nu) in the body of the seed and the cavity indicating the former position of the embryo (emb-s); note also the course of the ovular vascular bundle between the mesotesta and the endotesta (arrowhead). C, S174476; longitudinal (tangential) section through the fruit wall and seed coat showing polygonal cells of the endotesta (oi-e) with fibrous infillings, outlines of the mesotesta cells (oi-m) with thick walls, and fruit wall (fr); note that the cells are partly disintegrated, probably due to charring. Scale bars $=250 \mu \mathrm{m}(A, B), 125 \mu \mathrm{m}(C)$.

Repository. Palaeobotanical Collections, Department of Palaeobiology, Swedish Museum of Natural History, Stockholm, Sweden (S).

Type locality. Vale de Água (lat. $39^{\circ} 37^{\prime} 15^{\prime \prime} \mathrm{N}$, long. $\left.08^{\circ} 51^{\prime} 30^{\prime \prime} \mathrm{W}\right)$.

Type stratum and age. Early Cretaceous (late Aptian-early Albian; basal part of the Figueira da Foz Formation).

Occurrence in Portugal. Recorded only from the Vale de Água locality.

Description and remarks. The species is based on five specimens (S174169, S175139, S175141, S175159, S175160), all of which have a well-preserved fruit wall and were studied using SRXTM.

The fruits are elongate elliptical to ovate, or almost circular in lateral view, and ovate to circular in transverse section (figs. 6, 7A, 7B, 7D). The outer epidermis of the fruit wall consists of small cells with polygonal and equiaxial facets (fig. $6 \mathrm{~A}$, $6 B)$. Trichome bases are scattered over the fruit surface. Internally, cells of the fruit wall are usually collapsed. The inner epidermis of the fruit wall consists of narrow, elongate cells (fig. $7 E$ ). The stigmatic area is seen as a slightly raised protrusion (figs. $6 A-6 C, 6 E, 6 F, 7 A$ ). No pollen grains were observed on the stigma.

Each fruit contains two seeds arranged above each other along the ventral suture. In some cases both seeds apparently developed to maturity (fig. 6C, 6F), but in other specimens one seed is distinctly larger than the other (fig. $6 \mathrm{D}, 6 \mathrm{E}$ ). Seeds are similar in gen- eral organization to the type species. The micropylar opening in the testa is not exposed in any of the specimens.

The ovular vascular bundle is in the endotesta (figs. $6 \mathrm{D}, 6 \mathrm{~F}$, $7 B, 7 D)$, and the bundle on both sides of the chalaza appears to be equally well developed.

The testa is thick, mesotestal-endotestal, with the mesotesta thicker than the endotesta over most of the seed (figs. $6 \mathrm{C}-6 \mathrm{~F}$, $7 A-7 E)$. In the contact area between the two seeds, the mesotesta and the endotesta are of approximately the same thickness (fig. $7 A, 7 B$ ). The mesotesta is one cell layer thick and consists of sclerenchyma cells with scattered perforations. Over most of the seed, the cells of the mesotesta are palisade shaped (fig. $7 \mathrm{~A}$, $7 C, 7 E$ ), but where two seeds meet, they are almost cubic (fig. $7 A, 7 B$ ). The walls of the mesotesta cells are unevenly thickened, with the anticlinal walls thicker toward the inside and thinner toward the outside (fig. $7 C, 7 E-7 G$ ). Anticlinal cell walls are also slightly folded toward the outside but unfolded toward the inside (fig. $7 F, 7 G$ ). The endotesta is several cell layers thick, composed of small polygonal and equiaxial cells with endoreticulate infillings and a single central lumen (fig. $7 A-7 E$ ). The tegmen is thin, with cells of the outer epidermis narrowly elongate and radiating from the chalaza to the micropyle (fig. $6 F$ ). The surface of the seed cavity is smooth (figs. 6C-6F, 7A-7D).

Nutritive tissue was observed in three seeds (figs. 6C-6E, 7A, $7 B)$. Remains of the embryo are not preserved in any of the seeds, but an empty space in the nutritive tissue at the micropylar end of two of the seeds indicates that the embryo was tiny (fig. $7 B$ ). 

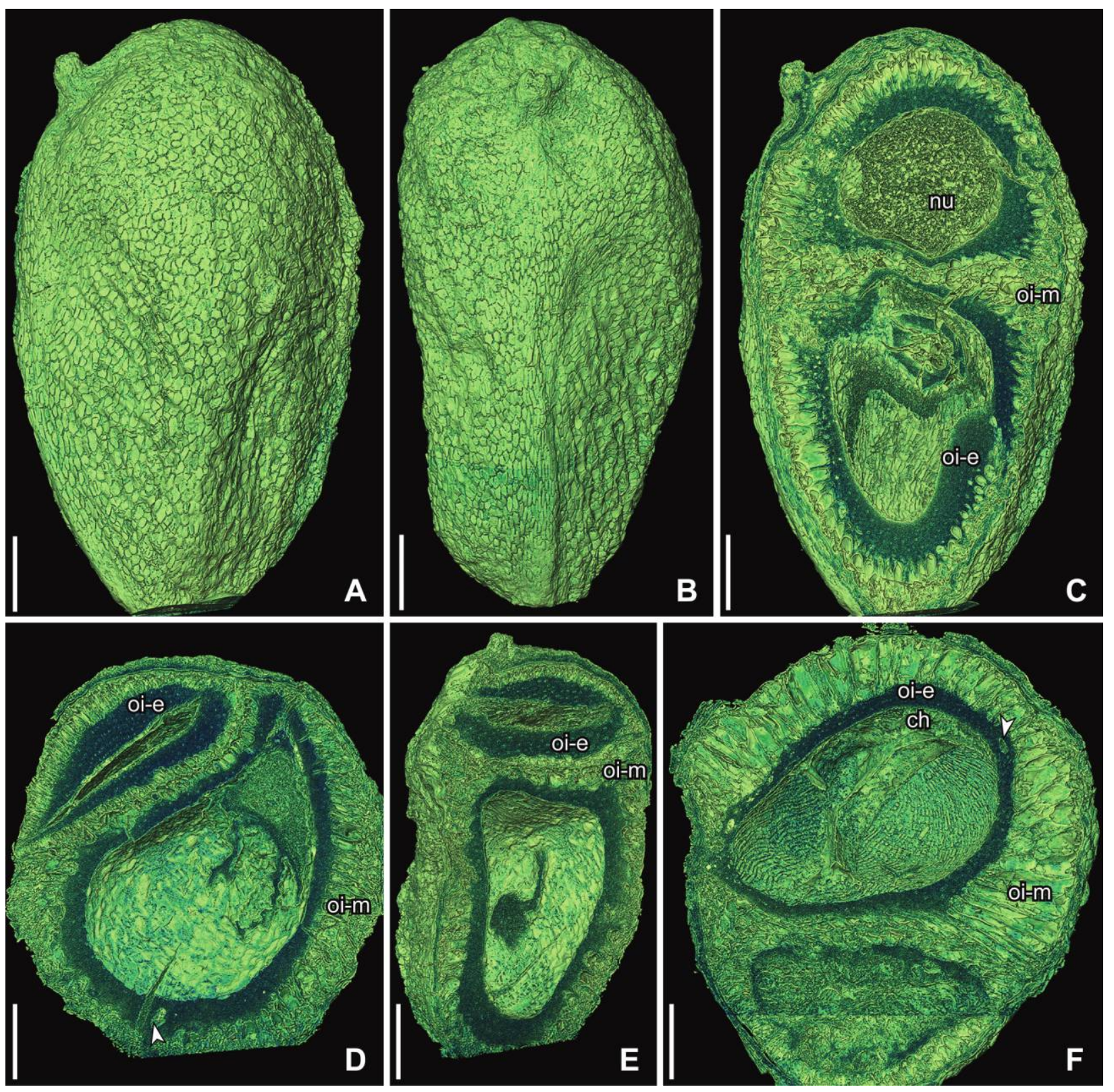

Fig. 6 Synchrotron radiation X-ray tomographic microscopy images (volume renderings) of fruits of Serialis elongata sp. nov. from the Early Cretaceous Vale de Água locality, Portugal, showing the surface and shape of thin-walled and indehiscent fruits and sections of fruits with two seeds; note the endotesta (oi-e) indicated in dark green; the mesotesta (oi-m) and fruit surface are in lighter green. A-C, Holotype, S174169 (sample Vale de Água 408). A, B, Lateral $(A)$ and ventral $(B)$ view of fruit showing the protruding stigmatic area; note polygonal epidermal cells of the fruit wall and elongated cells along the lower part of the ventral midline. $C$, Longitudinal section of fruit in the dorsiventral plane (cut at orthoslice yz0834) showing two seeds with nutritive tissue (nu) preserved in the upper seed; note the prominent, radially elongated cells of the mesotesta and the development of the mesotesta between the two seeds. D, E, S171541 (sample Vale de Água 408); longitudinal sections parallel to the dorsiventral plane $(D$, cut at orthoslice yz0750) and perpendicular to the dorsiventral plane ( $E$, cut at orthoslice xz1194) showing one well-developed and one poorly developed seed; note the massive, well-developed endotesta with an ovular vascular bundle (arrowhead) and the radially elongated cells of the mesotesta. F, S175159 (sample Vale de Água 19); longitudinal section parallel to the dorsiventral plane (cut at yz0842) showing the protruding stigmatic region, two seeds, the massive, well-developed endotesta, and the radially elongated cells of the mesotesta; note the ovular vascular bundle in the endotesta (arrowhead) and the distinctive elongated cells of the inner integument radiating from the chalaza $(\mathrm{ch})$. Scale bars $=250 \mu \mathrm{m}$. 

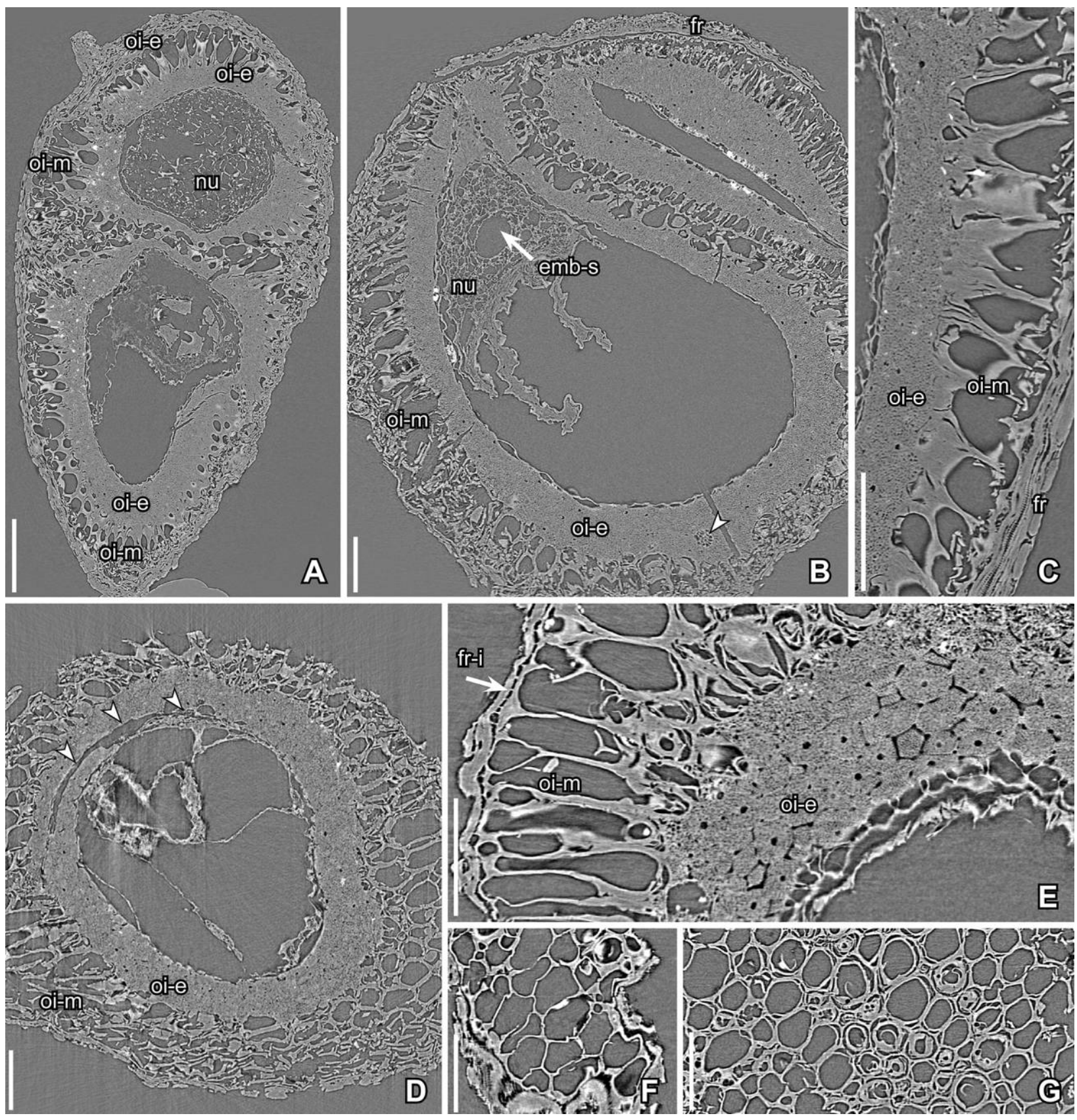

Fig. 7 Synchrotron radiation X-ray tomographic microscopy orthoslices of fruits of Serialis elongata sp. nov. from the Early Cretaceous Vale de Água locality, Portugal, showing the thin fruit wall (fr), large lumens of the radially elongated mesotesta cells (oi-m), the massive, well-developed endotesta (oi-e), the ovular vascular bundle extending in the endotesta (arrowheads), and the nutritive tissue (nu) surrounding the embryo cavity (emb-s). A, Holotype, S174169 (sample Vale de Água 408); longitudinal orthoslice (yz0800) of fruit parallel to the dorsiventral plane showing the protruding stigmatic area, the epidermal cells of the fruit wall, and two well-developed seeds; note the massive, well-developed endotesta, the large lumens of the radially elongated mesotesta cells, and the nutritive tissue preserved in the upper seed. B, S175141 (sample Vale de Água 408); longitudinal orthoslice (yz0713) of fruit parallel to the dorsiventral plane showing the thin fruit wall, one well-developed and one poorly developed seed, the well-developed mesotesta composed of cells with large lumens, and the massive endotesta that shows a section through an ovular vascular bundle; note the remains of nutritive tissue and a cavity indicating the former position of the embryo. C, Holotype, S174169 (sample Vale de Água 408); longitudinal orthoslice (yz0923) showing the fruit wall with distinct epidermal cells and the seed coat formed by a prominent mesotesta and endotesta; note that anticlinal walls of the radiating mesotesta cells thin toward the outside. D, S175159 (sample Vale de Água 19); transverse orthoslice (xy0662) through a seed showing the equiaxial to slightly elongated transverse sections through the radiating cells of the mesotesta and the massive endotesta; note the course of the ovular vascular bundle within the endotesta. E-G, S175139 (sample Vale de Água 383). E, Longitudinal (tangential) orthoslice (xz0492) of seed coat showing the thin inner epidermis of the fruit wall (fr-i), the radiating cells of the mesotesta (oi-m), and the massive endotesta (oi-e), composed of cells that are polygonal in section, have tiny cell lumens, and are filled with fibrous sclerified material. $F, G$, Longitudinal (tangential) orthoslices at different levels through the mesotesta showing the slightly wavy cell outlines toward the outside $(F, y z 0120)$ and the rounded, polygonal cell outlines toward the inside $(G, \mathrm{yz} 0300)$. Scale bars $=250 \mu \mathrm{m}(A)=125 \mu \mathrm{m}(B-G)$. 

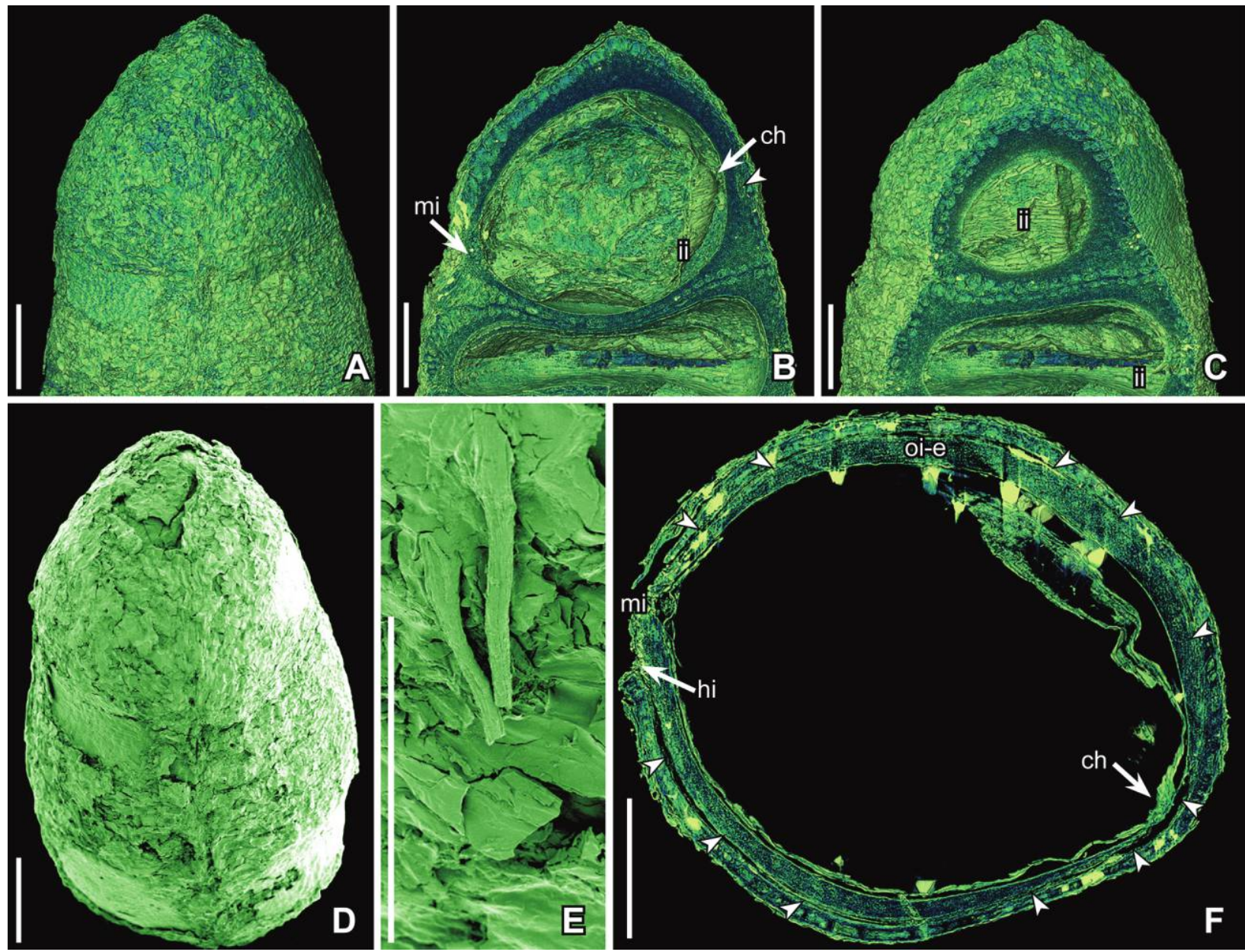

Fig. 8 Synchrotron radiation X-ray tomographic microscopy (volume renderings, $A-C, F$ ) and SEM $(D, E)$ images of a fruit of Serialis tenuitesta sp. nov. from the Early Cretaceous Famalicão locality, Portugal (sample Famalicão 25). Holotype, S170227, showing a thin-walled, indehiscent fruit with several seeds and a thin seed coat. $A$, Ventral view of the apex showing the outlines of two among a group of seeds. $B, C$, Longitudinal sections at two different levels parallel to the dorsiventral plane $(B$, cut near the middle of the fruit at orthoslice yz0879; $C$, cut near the surface of the fruit at yz1223) showing two seeds, the single layer of mesotestal cells, the massive endotesta, and the ovular vascular bundle (arrowhead) extending between the two layers of the testa; note the micropyle ( $\mathrm{mi}$ ) and the chalaza (ch) opposite each other and elongated cells of the inner integument (ii) radiating from the chalaza. $D$, Ventral view of the fruit showing the remains of the fruit wall. $E$, Detail of the fruit wall showing simple hairs. $F$, Transverse section (cut between orthoslices xy1575 and xy1600) showing the hilum (hi), the micropyle (mi), and the course of the ovular vascular bundle (arrowheads) between the mesotesta and the endotesta (oi-e) from the hilum to the chalaza (ch) and farther to the micropyle. Scale bars $=250 \mu \mathrm{m}(A-D), 125 \mu \mathrm{m}(E, F)$.

\section{Serialis tenuitesta E.M.Friis, P.R.Crane \& K.R.Pedersen sp. nov. (Figs. 8, 9)}

Derivation of specific name. From the thin testa (Latin tenui [thin, slender] and testa [outer seed coat]).

Specific diagnosis. As for the genus with the following additions: Fruit elongate elliptical in lateral view. Surface of fruit smooth. Stigma restricted. Seeds three. Endotesta and mesotesta of approximately the same thickness. Mesotesta one cell layer thick; cells short, cubic with thick anticlinal cell walls, evenly thickened from inside to outside; anticlinal walls not undulate; inner surface of anticlinal walls rough. Endoreticulate infillings of endotesta cells dense. Endotesta without interspersed cavities. Ovular vascular bundle in testa between mesotesta and endotesta. Testa surrounding micropyle not swollen. Outer epidermis of tegmen with narrow, elongate, thin-walled cells.

Dimensions. Length of fruit: $1.6 \mathrm{~mm}$; width of fruit (dorsiventrally): $1.08 \mathrm{~mm}$.

Holotype designated here. S170227 (Famalicão 25; illustrated here in figs. 8, 9).

Plant Fossil Names Registry. PFN000128 (for new species).

Repository. Palaeobotanical Collections, Department of Palaeobiology, Swedish Museum of Natural History, Stockholm, Sweden (S).

Type locality. Famalicão (lat. 39 $42^{\prime} 16^{\prime \prime} \mathrm{N}$, long. $\left.8^{\circ} 46^{\prime} 12^{\prime \prime} \mathrm{W}\right)$.

Type stratum and age. Early Cretaceous below the Figueira da Foz Formation; Early Cretaceous (late Aptian-early Albian or older). 

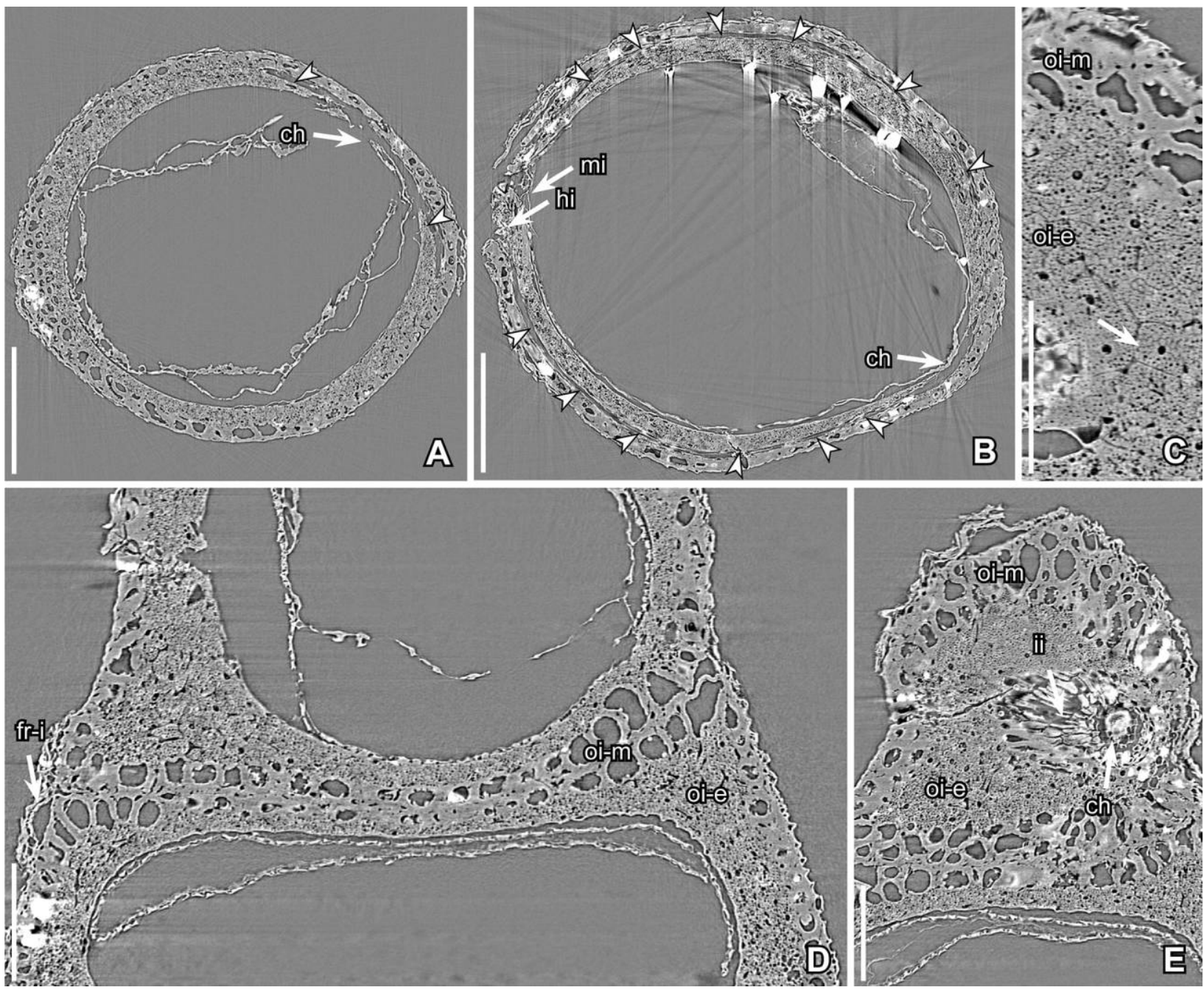

Fig. 9 Synchrotron radiation X-ray tomographic microscopy orthoslices of a fruit of Serialis tenuitesta sp. nov. from the Early Cretaceous Famalicão locality, Portugal (sample Famalicão 25). Holotype, S170227, showing details of the mesotesta (oi-m), the endotesta (oi-e), and the course of the ovular vascular bundle (arrowheads) extending between the mesotesta (oi-m) and the endotesta (oi-e) from the hilum (hi) to the chalaza (ch) and farther to the micropyle (mi) on the other side. A, Transverse orthoslice (xy0786) through the terminal seed of a group of seeds, showing the chalaza and the ovular vascular bundle on both sides of the chalaza; note the single layer of large empty cells that comprises the mesotesta and the massive endotesta. $B$, Transverse orthoslice (xy1583) through the seed next to the terminal seed showing the course of the ovular vascular bundle. C, Longitudinal (tangential) orthoslice (yz1310) through the seed coat showing thick-walled cells of the mesotesta with open, rounded lumens and crenulate surfaces of the anticlinal walls and heavily sclerified endotesta cells with distinct endoreticulate fibers (arrow). D, Longitudinal orthoslice (xz1265) showing the junction between two tightly coherent seeds; note that both the mesotesta and the endotesta are well developed between the two adjacent seeds but thinner than over other parts of the seed; note also fragments of the fruit wall with inner epidermis (fr-i) that have loosened from the seeds. E, Longitudinal (tangential) orthoslice (xz1459) through the chalazal region showing the mesotesta, the endotesta, and the thin, slightly elongate cells of the inner integument (ii) radiating from the chalaza. Scale bars $=250 \mu \mathrm{m}(A, B), 125 \mu \mathrm{m}(C-E)$.

Occurrence in Portugal. Recorded only from the Famalicão locality.

Description and remarks. The species is based on a single specimen (S170227), which was studied with both SRXTM and SEM.

The fruit is elongate elliptical in lateral view and almost circular in transverse section (fig. $8 A, 8 D, 8 F$ ). The fruit wall is thin and collapsed and only partly preserved (figs. $8 A, 8 D, 9 D$ ). The stigmatic area is indistinct. Pollen grains were not observed attached to the fruit. The outer epidermis of the fruit wall consists of small cells with polygonal and equiaxial facets (fig. 8A, 8D). Short, stiff trichomes are scattered over the fruit surface (fig. $8 D$, $8 E)$. The inner epidermis of the fruit wall consists of narrow, elongate cells, and where the fruit wall is abraded, these are seen as oblique transverse striations on the outer surface of the seeds (fig. 8A, 8C).

The fruit contains three seeds arranged above each other along the ventral suture. The seed in the middle is smaller than the two other seeds (fig. 8B, 8C). Seeds are similar in general organization to the type species. The micropylar opening in the testa is covered 
by remains of the fruit wall, and the shape of the opening is not clear. The ovular vascular bundle is between the endotesta and the mesotesta (figs. 8F, 9A, 9B).

The testa is thick, mesotestal-endotestal, with the mesotesta and the endotesta of approximately the same thickness over most of the seed (figs. $8 B, 8 C, 8 F, 9 A, 9 B$ ), including in regions where two seeds meet (figs. $8 B, 8 C, 9 D$ ). The mesotesta is one cell layer thick and consists of almost cubic sclerenchyma cells. The cell walls are thick, with scattered perforations and an uneven, rough inner surface. The anticlinal walls are of almost equal thickness from the inside to the outside and are unfolded (fig. 9). The endotesta is several cell layers thick, composed of small polygonal and equiaxial cells with endoreticulate infillings and a single central lumen (fig. 9C-9E). The tegmen is thin, with an outer epidermis of narrowly elongate cells (figs. $8 C, 9 E$ ). The surface of the seed cavity is smooth (figs. $8 B, 8 F, 9 A, 9 B$ ). Embryo and nutritive tissue were not preserved in any of the seeds.
Serialis communis E.M.Friis, P.R.Crane \& K.R.Pedersen sp. nov. (Figs. 10-12)

Derivation of specific name. From the abundant and common occurrence in the Famalicão mesofossil flora, Portugal (Latin communis [common]).

Specific diagnosis. As for the genus with the following additions: Fruit elongate elliptical to circular in lateral view. Surface of fruit smooth to slightly verrucate. Stigma restricted. Seeds one to six. Mesotesta much thicker than endotesta. Mesotesta one cell layer thick; cells palisade shaped with very thick, evenly thickened anticlinal walls; anticlinal walls not undulate and with smooth inner surfaces. Endoreticulate infillings of the endotesta cells weakly developed. Endotesta without interspersed cavities. Ovular vascular bundle between endotesta and mesotesta. Testa surrounding micropyle not swollen. Outer epidermis of tegmen with narrow, elongate fibers with reticulate thickenings.
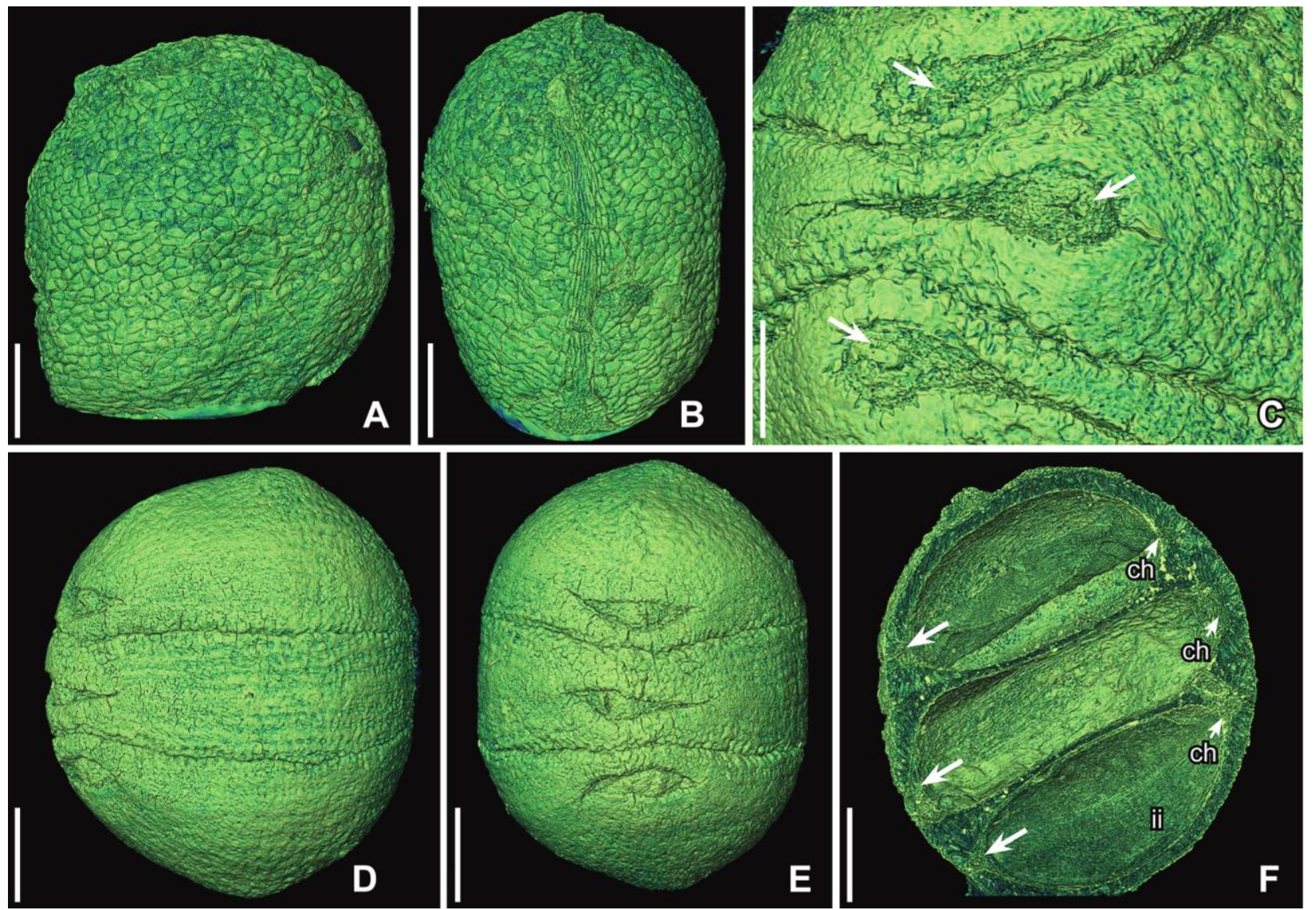

Fig. 10 Synchrotron radiation X-ray tomographic microscopy images (volume renderings) of a fruit and seeds of Serialis communis sp. nov. from the Early Cretaceous Famalicão locality, Portugal (sample Famalicão 25). A, B, S170228; lateral $(A)$ and ventral $(B)$ view of thin-walled, indehiscent fruit showing apical stigmatic region, prominent, well-preserved epidermal cells, and elongated epidermal cells running to the base of the fruit along the ventral line. C, S170229; detail of the hilar and micropylar areas on the ventral surface of a group of three coherent seeds; note that the micropyles (arrows) are formed by the inner integument and that the micropyles of adjacent seeds alternate. D, E, Holotype, S170109; lateral $(D)$ and ventral $(E)$ view of a group of three coherent seeds; note that the hilar and micropylar areas of adjacent seeds alternate. $F$, zS175136; longitudinal section through a thin-walled indehiscent fruit (cut at orthoslice yz20703) showing the stigmatic area and a group of three coherent seeds with their micropyles (arrows) oriented toward the ventral fruit surface and the chalazas (ch) in the opposite position; note the narrow, elongate cells of the inner integument (ii) radiating from the chalaza to the micropyle. Scale bars $=250 \mu \mathrm{m}(A, B, D-F), 125 \mu \mathrm{m}(C)$. 

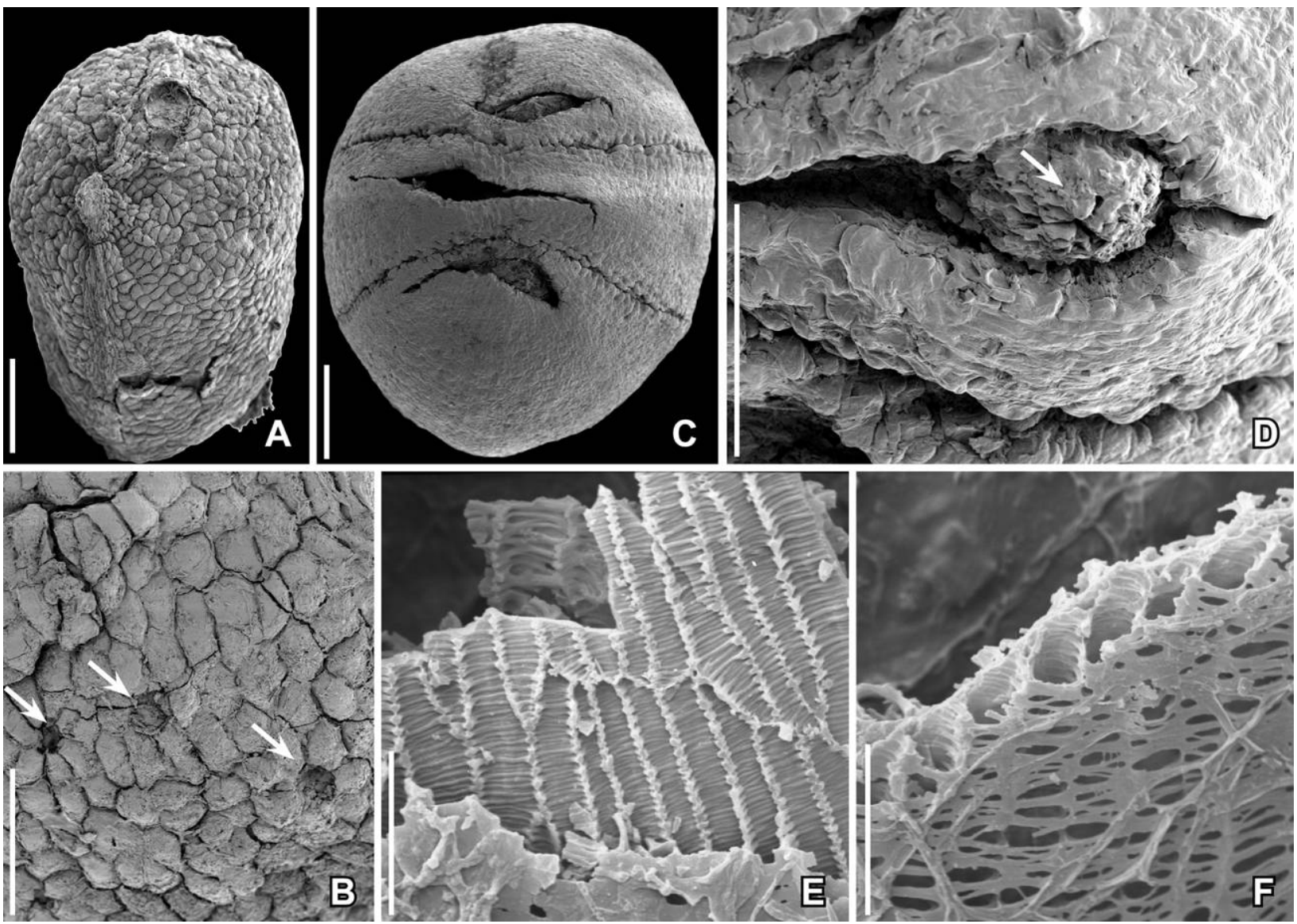

Fig. 11 SEM images of a fruit and seeds of Serialis communis sp. nov. from the Early Cretaceous Famalicão locality, Portugal (sample Famalicão 25), showing details of the fruit wall, the micropylar/hilar region, and the tegmen. $A, B, \mathrm{~S} 170228$; fruit in figure $10 A$ in oblique ventral view showing the stigmatic area and prominent epidermal cells of the fruit wall and trichome bases ( $B$, arrows); note the elongated cells running to the base of the fruit along the ventral line. C, S170095; ventral view of three closely coherent seeds showing the alternating hilar/ micropylar areas. $D, S 170229$; detail of the hilar/micropylar area on the ventral surface of a seed; note that the micropyle (arrow) is formed by the inner integument. E, F, Detail of inner integument (tegmen) showing prominent narrow, elongate cells of the outer tegmen with internal thickenings ( $E$, inner walls exposed, S105148; $F$, section of outer tegmen, S105149). Scale bars $=250 \mu \mathrm{m}(A, B), 125 \mu \mathrm{m}(C, D), 25 \mu \mathrm{m}(E, F)$.

Dimensions. Length of fruit: 1.1-2 mm; width of fruit (dorsiventrally): 1.0-1.6 mm.

Holotype designated here. S170109 (Famalicão 25; illustrated here in fig. 10D, 10E).

Plant Fossil Names Registry. PFN000129 (for new species).

Paratypes designated here. S105127-105174, S170228, S170229, S174095, S174439, S174815, S174816-S174818, S175121-S175136, S175145, S175151 (Famalicão sample 25; up to 400 specimens stored under the same number).

Repository. Palaeobotanical Collections, Department of Palaeobiology, Swedish Museum of Natural History, Stockholm, Sweden (S).

Type locality. Famalicão (lat. $39^{\circ} 42^{\prime} 16^{\prime \prime} \mathrm{N}$, long. $\left.8^{\circ} 46^{\prime} 12^{\prime \prime} \mathrm{W}\right)$.

Type stratum and age. Below the Figueira da Foz Formation; Early Cretaceous (late Aptian-early Albian or older).

Occurrence in Portugal. Occur abundantly at the Famalicão locality; the species is otherwise rare, with specimens occurring at the Arazede, Catefica, and Vale de Água localities.

Description and remarks. The species is based on more than 2230 specimens; 18 specimens were studied using SRXTM
(S170109, S170228, S170229, S174095, S174439, S174490, S174814, S174816, S174817, S175129, S175130-S175133, S175135, S175136, S175145, S175151), two specimens were embedded in resin and serial sectioned (S105142, S105143). Many specimens have a well-preserved fruit wall.

The fruits are elliptical to circular in lateral view and ovate to circular in transverse section (figs. 10A, 10B, 10D-10F, 11A, $11 B)$. The fruit wall consists of thin-walled parenchyma cells. The outer epidermis of the fruit wall consists of small cells with polygonal and equiaxial facets (figs. $10 A, 10 B, 11 A$ ) that are sometimes raised, giving the fruit surface a slightly verrucate appearance. Small scattered holes in the epidermis indicate the position of trichomes (fig. 11B). The inner epidermis of the fruit wall consists of narrow, elongate fibers that are sometimes seen as transverse striations on the seed surface where the fruit wall has been abraded. The stigmatic area is restricted and slightly raised (figs. 10A, 10B, 11A). Pollen grains were not observed on any of the specimens.

Each fruit contains one to six seeds (figs. 10D, 10E, 11C). The number of seeds per fruit was counted for 745 specimens. Of 

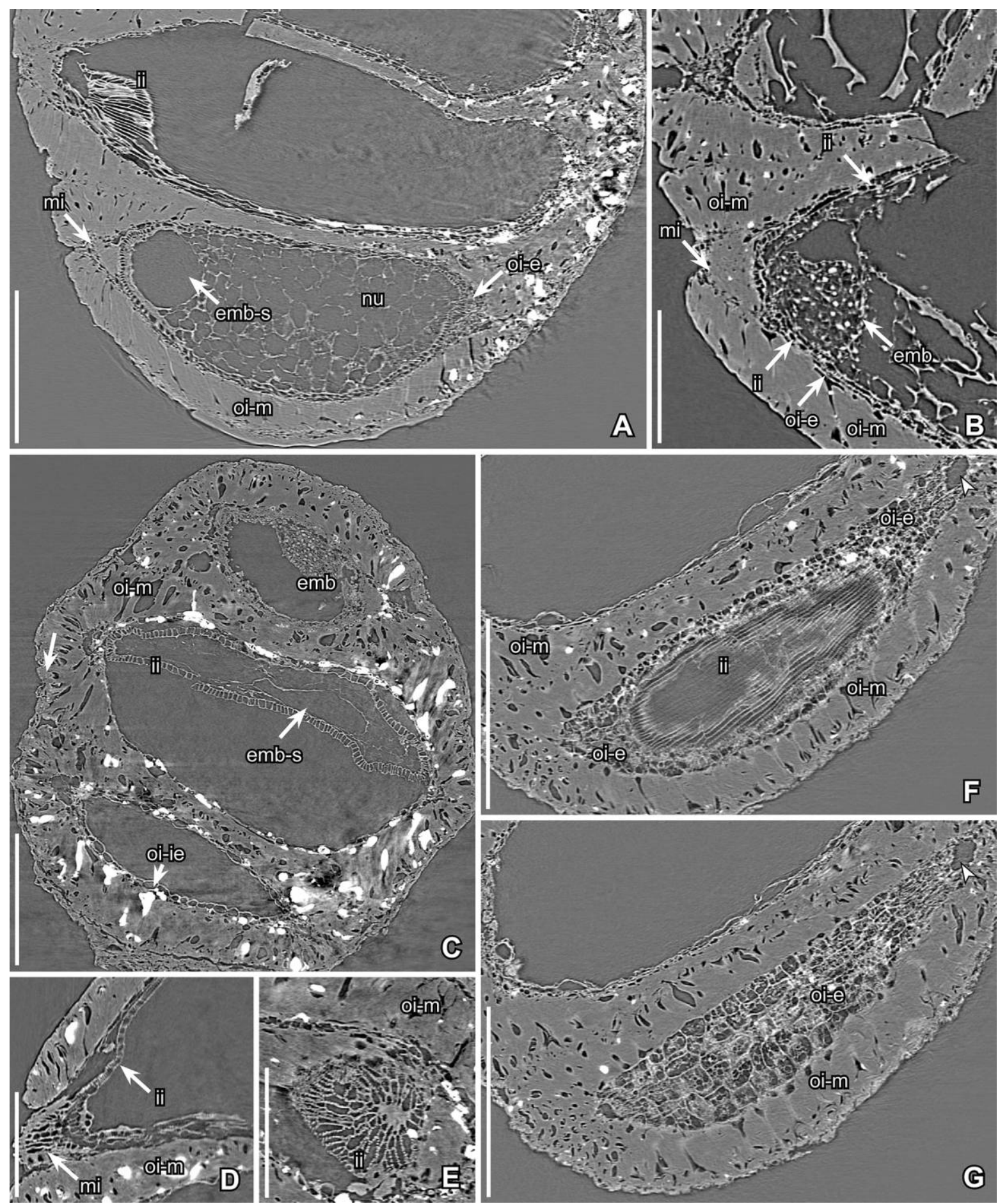

Fig. 12 Synchrotron radiation X-ray tomographic microscopy images (orthoslices) of fruits and seeds of Serialis communis sp. nov. from the Early Cretaceous Famalicão locality, Portugal (sample Famalicão 25), showing seed coat consisting mainly of a thick mesotesta (oi-m) with a thin endotesta (oi-e) and a tegmen (inner integument, ii) with a distinct outer epidermis of narrow, elongate cells; several specimens show remains of nutritive tissue (nu), the embryo (emb), or cavity from the embryo (emb-s); note the micropyle (mi) formed from the inner integument. A, S175132; longitudinal orthoslice (yz0545) in the dorsiventral plane through a pair of tightly coherent seeds showing the thick mesotesta, the thin endotesta, the thin tegmen, and the well-developed nutritive tissue with an embryo cavity adjacent to the micropyle. $B$, S170229; longitudinal orthoslice (yz0789) through the hilar/micropylar region in the dorsiventral plane showing the micropyle protruding through the mesotesta, the thin endotesta, and the delicate tegmen; note the small, poorly developed embryo adjacent to the micropyle and the remains of the nutritive tissue in which it is embedded. C, S174817; longitudinal orthoslice (yz0415) perpendicular to the dorsiventral plane through three tightly coherent seeds showing the thick mesotesta, the prominent inner epidermis of the endotesta (oi-ie), and the well-preserved tegmen; note the embryo cavity in the middle seed and the embryo in the upper seed. D, S174095; longitudinal orthoslice (yz1020) through the hilar/micropylar region showing the cells of the tegmen forming the micropyle, which protrudes through the mesotesta. E, S174817; longitudinal tangential orthoslice (xz0200) showing the cells of the tegmen converging toward the micropyle and surrounded by the thick-walled cells of the mesotesta. F, G, S175136; longi- 
these, six have a single seed, 13 have two seeds, 590 have three seeds, 130 have four seeds, and five have six seeds. The seeds are similar in general organization to the type species (figs. 10C$10 F, 11 C, 11 D, 12 A-12 D)$. The micropyle protrudes through a transversely aligned, elongate, drop-shaped opening in the outer integument (figs. 10C-10E, 11C, 11D).

The ovular vascular bundle is between the endotesta and the mesotesta, and the bundle is apparently equally well developed on both the raphal and antiraphal sides of the seed.

The testa is thick, mesotestal-endotestal, with the mesotesta much thicker than the endotesta (fig. 12). The mesotesta is one cell layer thick and consists of palisade-shaped sclerenchyma cells (fig. 12). The cell walls are thick, and the anticlinal walls are of almost equal thickness from the inside to the outside; they are straight without undulations and have smooth inner surfaces. The endotesta is thin, particularly in the contact zone between adjacent seeds, but is slightly thicker around the micropyle and the chalaza (fig. 12A, 12F, 12G). It consists of several small polygonal and equiaxial cells with weakly developed endoreticulate infillings (fig. 12F, 12G). The inner epidermis of the testa consists of thin-walled, slightly elongate cells that are usually collapsed (fig. 12C). The tegmen is thin, with the outer epidermis consisting of narrow, elongate cells that radiate from the chalaza to the micropyle and have reticulate thickenings (figs. 10F, 11E, 11F, 12A-12F). The surface of the seed cavity is smooth (figs. 10F, 12A, 12C).

Remains of embryo and nutritive tissue were observed in several specimens (fig. 12A-12C). The embryo is tiny, with small cells containing a central body, which is probably the remains of the nucleus. The nutritious tissue is cellular, composed of small, thin-walled, polygonal, and equiaxial cells.

\section{Serialis crassitesta E.M.Friis, P.R.Crane \& K.R.Pedersen sp. nov. (Figs. 13, 14)}

Derivation of specific name. From the thick testa (Latin cassus [thick] and testa [outer seed coat].

Specific diagnosis. As for the genus with the following additions: Fruit elliptical to circular in lateral view. Surface of fruit smooth. Stigma restricted. Seeds four to five. Endotesta much thicker than mesotesta. Mesotesta one cell layer thick; cells cubic; anticlinal walls very thin and undulate toward the inside and outside, thick in the median part with smooth inner surfaces. Endoreticulate infillings of the endotesta cells dense. Endotesta without interspersed cavities. Ovular vascular bundle in endotesta. Testa surrounding micropyle not swollen. Outer epidermis of tegmen with thin-walled, slightly elongate cells.

Dimensions. Length of fruit: $1.4-1.7 \mathrm{~mm}$; width of fruit (dorsiventrally): $1.2-1.6 \mathrm{~mm}$.

Holotype designated here. S170231 (Famalicão 25; illustrated here in figs. $13 A-13 D, 14 D)$.

Plant Fossil Names Registry. PFN000130 (for new species).

Paratypes designated here. S153509, S174815, S174818, S175124-S175127 (Famalicão sample 25).
Repository. Palaeobotanical Collections, Department of Palaeobiology, Swedish Museum of Natural History, Stockholm, Sweden (S).

Type locality. Famalicão (lat. $39^{\circ} 42^{\prime} 16^{\prime \prime} \mathrm{N}$, long. $\left.8^{\circ} 46^{\prime} 12^{\prime \prime} \mathrm{W}\right)$.

Type stratum and age. Below the Figueira da Foz Formation; Early Cretaceous (late Aptian-early Albian or older).

Occurrence in Portugal. Common at the Famalicão locality and recorded also from the Catefica and Vale de Água localities.

Description and remarks. The species is based on more than 375 specimens; five specimens were studied using SRXTM (S153509, S170230, S170231, S174815, S174818). Many specimens have the fruit wall preserved.

The fruits are elliptical to circular in lateral view and typically circular in transverse section (figs. 13A-13E, 14A, 14B, 14D, $14 F)$. The outer epidermis of the fruit wall consists of small cells with polygonal and equiaxial facets. Trichome bases were not observed. The fruit wall consists of thin-walled parenchyma cells. The inner epidermis of the fruit wall consists of narrow, elongate fibers that are sometimes seen as a transverse striations on the seed surface where the fruit wall has been abraded. The stigma is slightly raised (fig. 13C, 13D). Pollen grains were not observed on any of the specimens.

Each fruit contains mostly four, sometimes five, seeds. In both four-seeded and five-seeded specimens, the apical and basal seeds are often underdeveloped (fig. 13B). Seeds are similar in general organization to the type species. The shape of the micropylar opening in the outer integument is often concealed by remains of the fruit wall adhering to the seeds (fig. 13A, 13C). In abraded specimens, the micropylar openings are seen as transversely aligned and drop-shaped slits that are oriented alternately on adjacent seeds (fig. 14A). The ovular vascular bundle is in the endotesta.

The testa is thick, mesotestal-endotestal, with the mesotesta much thinner than the endotesta (fig. 14D-14F). The mesotesta is one cell layer thick and consists of cubic sclerenchyma cells (fig. 14F). The anticlinal walls of the mesotesta cells are thick in the middle but very thin toward the inside and outside, where they are also slightly undulate (figs $13 E, 13 F, 14 H$ ). The delicate inner and outer parts of the anticlinal walls makes the tissue vulnerable to breakage. The mesotesta is often abraded, leaving a surface pattern of finely undulate cell walls (figs. 13E, 13F, $14 B, 14 C)$. The wall also breaks easily close to, but not along, the contact areas between two coherent seeds (fig. 14E, 14F), leaving a rough surface of the broken cell walls. The two seeds never separate along their line of coherence. The endotesta is several cell layers thick (fig. 14), composed of small polygonal and equiaxial cells with densely developed endoreticulate infillings (fig. 14G). The inner epidermis of the testa consists of thinwalled, slightly elongate cells that are usually collapsed. The tegmen is thin, with the outer epidermis consisting of slightly elongate cells that radiate from the chalaza to the micropyle (fig. $13 B, 13 D$ ). The surface of the seed cavity is smooth (figs. $13 B, 13 D, 14 D$ ).

tudinal tangential orthoslices at two different levels ( $F$, yz1020; $G$, yz1043) through the seed coat showing narrow, elongate cells of the tegmen, the thin endotesta, and the thick mesotesta; note the poorly developed fibrous infillings of sclerified material in the endotesta cells. Scale bars $=250 \mu \mathrm{m}$ $(A, C, F, G), 125 \mu \mathrm{m}(B, D, E)$. 

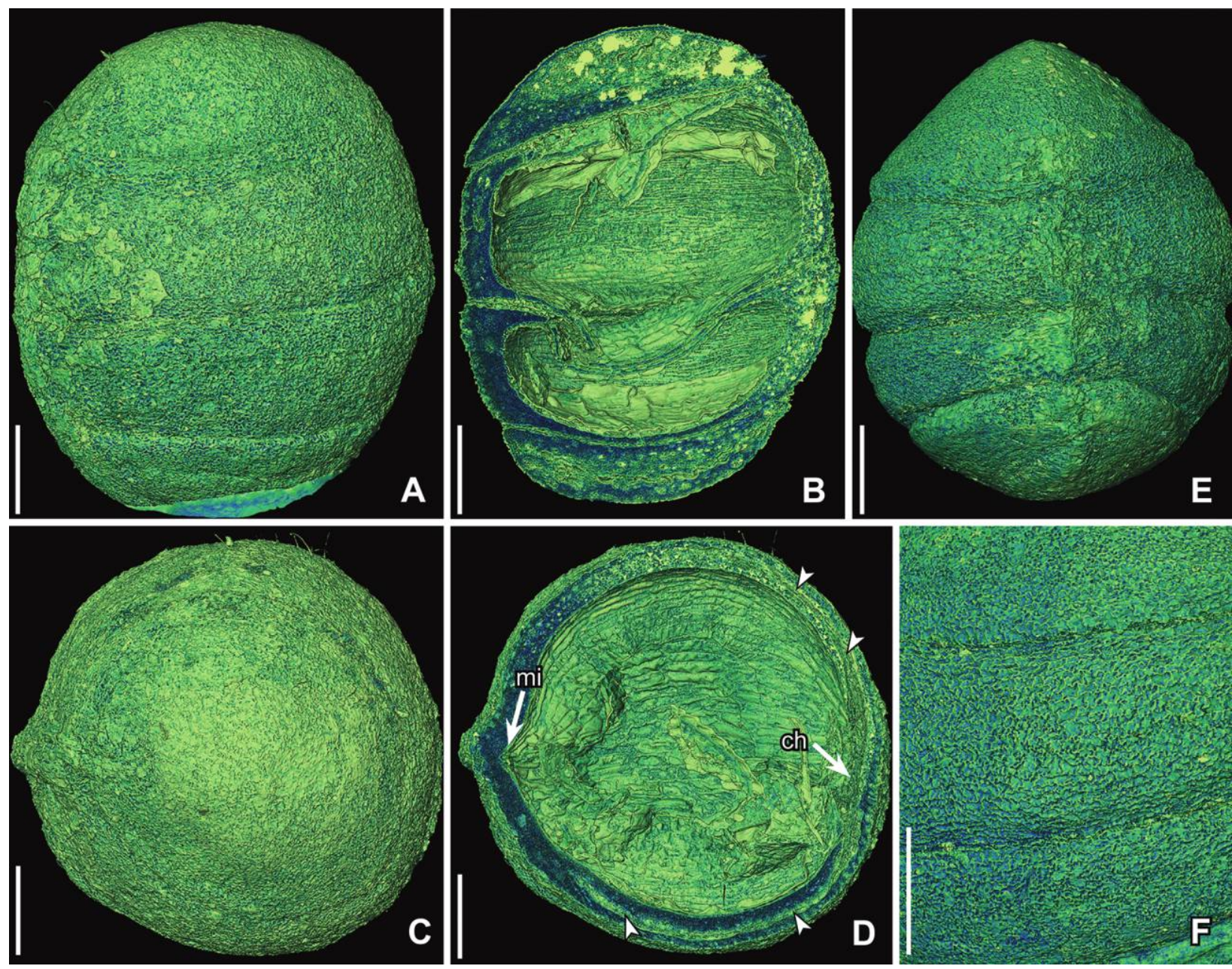

Fig. 13 Synchrotron radiation X-ray tomographic microscopy images (volume renderings) of fruits and seeds of Serialis crassitesta sp. nov. from the Early Cretaceous Famalicão locality, Portugal (sample Famalicão 25), showing abraded fruits with four seeds; note the chalaza (ch) opposite the micropyle (mi) and the extension of the ovular vascular bundles (arrowheads) on both sides of the chalaza; the endotesta is marked in dark blue. A-D, Holotype, S170231. A, Lateral view of a group of four coherent seeds with only fragments of the fruit wall remaining, showing the rough surface and indistinct junctions between the seeds. B, Longitudinal section of the four coherent seeds (cut at orthoslice yz0990) showing uneven development of the central and terminal seeds. C, Apical view of seeds showing the protruding ventral suture and seed surface with the thin undulating anticlinal walls of the mesotesta cells. $D$, Transverse section through one of the seeds (cut at orthoslice xy0770) showing the protruding ventral line and the course of the ovular vascular bundle in the endotesta on both the raphal and antiraphal sides of the seed; note the slightly elongate cells of the tegmen radiating from the chalaza to the micropyle. $E, F, S 170230$; ventral view $(E)$ of four coherent seeds with remains of the fruit wall obscuring the micropylar/hilar areas and details of the seed surface $(F)$ showing the thin undulating anticlinal walls of the mesotesta cells. Scale bars $=250 \mu \mathrm{m}$.

Remains of a cellular nutritive tissue were observed in several specimens, but none of the specimens showed the remains of an embryo cavity or embryo.

\section{Serialis grossa E.M.Friis, P.R.Crane \& K.R.Pedersen sp. nov. (Figs. 15, 16)}

Derivation of specific name. From the swollen form of the seeds (Latin grossus [fat, thick]).

Specific diagnosis. As for the genus with the following additions: Fruit broadly elliptical to circular in lateral view. Surface of fruit smooth. Stigma restricted. Seeds three to four. Mesotesta and endotesta of approximately the same thickness. Mesotesta thin in the contact region between seeds. Mesotesta one cell layer thick; cells cubic with anticlinal walls very thick toward the outside, and thin and undulate toward the inside. Endoreticulate infillings of the endotesta cells dense. Endotesta thick with interspersed cavities (possible oil cells) over most of the seed; endotesta thinner in the contact region between two seeds. Ovular vascular bundle in the endotesta. Testa surrounding micropyle swollen.

Dimensions. Length of fruit: 1.7-2.56 mm; width of fruit (dorsiventrally): 2.2-2.4 mm. 
Holotype designated here. S175150 (Famalicão 25; illustrated here in figs. $15 C, 15 D, 16 A-16 D)$.

Plant Fossil Names Registry. PFN000131 (for new species).

Paratypes designated here. S174813, S175193-S175195 (Famalicão sample 25).

Repository. Palaeobotanical Collections, Department of Palaeobiology, Swedish Museum of Natural History, Stockholm, Sweden (S).

Type locality. Famalicão (lat. $39^{\circ} 42^{\prime} 16^{\prime \prime} \mathrm{N}$, long. $\left.8^{\circ} 46^{\prime} 12^{\prime \prime} \mathrm{W}\right)$.

Type stratum and age. Below the Figueira da Foz Formation; Early Cretaceous (late Aptian-early Albian or older).

Occurrence in Portugal. Recorded only from the Famalicão locality.

Description and remarks. The species is based on six specimens, two of which were studied using SRXTM (S174813, S175150).

Both specimens studied using SRXTM are abraded, and there is no indication of the structure of the fruit wall or the nature of the stigma. No pollen grains were observed on the surface of the fruits.

One specimen has three seeds (fig. 15A, 15B). The other specimen consists of four seeds (fig. 15C,15D). All seeds appear to be equally developed. The seeds are similar in general organization to the type species (fig. 15B, 15D).

The ovular vascular bundle is in the endotesta (fig. 16C, 16D), and the bundle on both sides of the chalaza appears to be equally developed.

The testa is thick, mesotestal-endotestal, with the mesotesta and the endotesta of almost equal thickness (fig. 16A-16D). The mesotesta is one cell layer thick and consists of tall, palisadeshaped sclerenchyma cells (fig. 16A-16D). The anticlinal cell walls are thick, except close to the inner and outer surface where they are thin and undulate. The endotesta is several cell layers thick. It is thickest near the micropyle and the chalaza and is composed of small polygonal and equiaxial cells with dense endoreticulate infillings. Interspersed in the endotesta are large cavities that possibly represent the remains of oil cells (fig. 16A$16 D)$. The inner epidermis of the testa is thin, consisting of slightly elongate thin-walled cells that are typically collapsed. The tegmen is thin, but cellular details are unknown.

There are no remains of embryo and nutritive tissue in any of the seeds studied using SRXTM.

\section{Serialis undata E.M.Friis, P.R.Crane \& K.R.Pedersen sp. nov. (Figs. 17, 18)}

Derivation of specific name. From the wavy-rugulate surface of the mesotesta in the contact regions between two seeds (Latin undatus [wavy].

Specific diagnosis. As for the genus with the following additions: Fruit elliptical to circular in lateral view. Surface of fruit slightly rugulate. Seeds three. Mesotesta thicker than the endotesta. Mesotesta one cell layer thick; cells palisade shaped of uneven height resulting in a rugulate surface, anticlinal walls not undulate. Endoreticulate infillings of endotesta cells weakly developed. Endotesta without interspersed cavities. Endotestal cells fibrous. Ovular vascular bundle between mesotesta and endotesta. Testa surrounding micropyle not swollen.

Dimensions. Length of fruit: unknown; width of fruit (dorsiventrally): $1.3 \mathrm{~mm}$.
Holotype designated here. S175147 (Famalicão 25; illustrated here in figs. $17 A-17 C, 18 A, 18 B)$.

Plant Fossil Names Registry. PFN000132 (for new species).

Paratypes designated here. S175148, S175149, S175183 (Famalicão sample 25).

Repository. Palaeobotanical Collections, Department of Palaeobiology, Swedish Museum of Natural History, Stockholm, Sweden (S).

Type locality. Famalicão (lat. 39 $42^{\prime} 16^{\prime \prime} \mathrm{N}$, long. $8^{\circ} 46^{\prime} 12^{\prime \prime} \mathrm{W}$ ). Type stratum and age. Below the Figueira da Foz Formation; Early Cretaceous (late Aptian-early Albian or older).

Occurrence in Portugal. Recorded only from the Famalicão locality.

Description and remarks. The species is based on $11 \mathrm{spec}-$ imens, of which three were studied using SRXTM (S175147S175149). Remains of the fruit wall are preserved in one specimen, but the fruit epidermis and stigma are not preserved. No pollen grains were observed on the surface of the fruit.

All specimens are fragmentary (fig. 17) and consist of one or two seeds that have broken apart from an aggregation that apparently originally consisted of three seeds. Most of the specimens are median seeds that are typically very flat (fig. 17A$17 C)$, few are terminal seeds that typically have a flat inner face and a rounded outer face (fig. 17D-17F), and one specimen has both a terminal seed and a median seed. The fruits were probably almost spherical. The outer surface of the fruit is faintly rugulate (fig. $17 D-17 F$ ). The inner epidermis of the fruit wall consists of narrow, elongate fibers that in abraded areas appear as a transverse striations on the seed surfaces (fig. 17F).

The seeds are similar in general organization to the type species. Although they usually occur isolated, the contact surfaces appear fragmented, and isolated seeds seem to have broken away from tightly coherent seed units through a fracture plane along the rough surface of the mesotesta. The micropylar-hilar opening in the testa is seen as a transversely aligned slit (fig. 17B, 17E). The ovular vascular bundle is between the endotesta and the mesotesta (fig. 18B).

The testa is thick, with the mesotesta thicker than the endotesta (fig. 18B), particularly in the contact region between two seeds, where it is much thicker (fig. 18A, 18C). The mesotesta is one cell layer thick and consists of tall palisade-shaped sclerenchyma cells. In the contact regions between two seeds, the cells of the mesotesta cells are very uneven in height, resulting in the mesotesta having a strongly rugulate surface (fig. $17 A-17 E$ ). The endotesta is several cell layers thick, composed of small fibrous cells that appear to be only loosely connected (fig. 18A, 18B). The infillings of the endotestal cells appear fibrous and are only weakly developed. The tegmen is thin, but no cellular details are preserved.

Fragmentary patches of nutritive tissue were observed in specimen S175147 (fig. 18A), but no indications of an embryo were observed.

\section{Serialis reticulata E.M.Friis, P.R.Crane \& K.R.Pedersen sp. nov. (Figs. 19, 20)}

Derivation of specific name. From the reticulate surface of the fruits (Latin reticulatus [reticulate]).

Specific diagnosis. As for the genus with the following additions: Fruit broadly elliptical in lateral view. Surface of fruit finely reticulate. Stigma restricted. Seeds two, rarely one. Mesotesta 

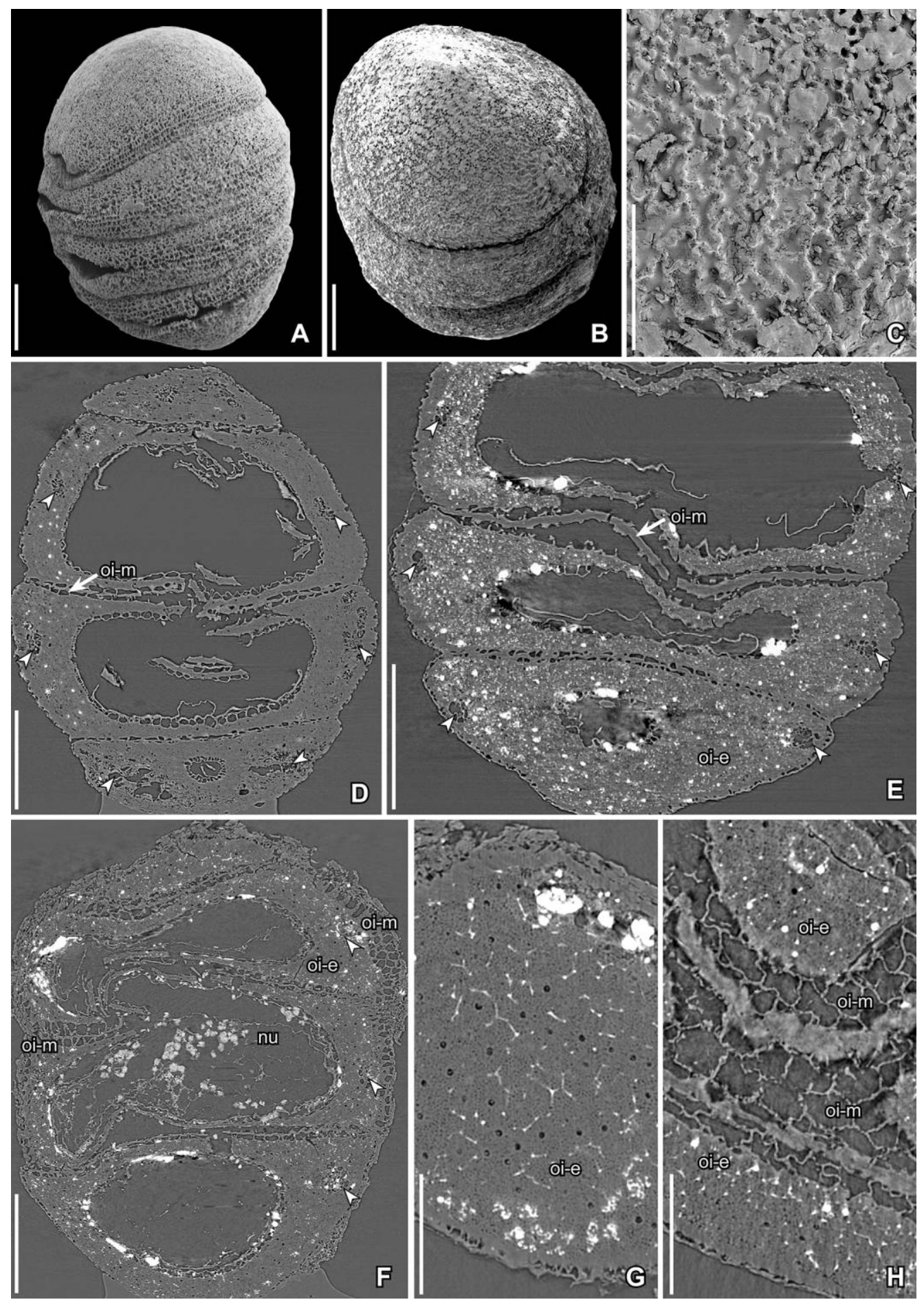

Fig. 14 SEM images $(A-C)$ and synchrotron radiation X-ray tomographic microscopy images (orthoslices, $D-H$ ) of seeds of Serialis crassitesta sp. nov. from the Early Cretaceous Famalicão locality, Portugal (Famalicão sample 25), showing rough seed surface formed by the thin undulating anticlinal cell walls of the thin mesotesta (oi-m) and the massive endotesta (oi-e) formed by polygonal cells with endoreticulate infillings; note ovular vascular bundles (arrowheads) in the endotesta and separation of seeds along the weak mesotestal cells. $A, \mathrm{~S} 105147$; four tightly coherent seeds without the fruit wall preserved showing the alternating micropylar/hilar areas. B, C, E, S170230. $B$, Oblique apical view of the four tightly coherent seeds in figure $13 E$ showing fragmentary remains of the fruit wall covering the mesotesta cells with sinuous anticlinal walls. C, Detail of the seed surface. D, Holotype, S170231; longitudinal orthoslice (xz0416) perpendicular to the dorsiventral plane through a group of four seeds showing the massive endotesta and the weakly developed mesotesta that extends between the seeds; note the inner epidermis of the endotesta and the ovular vascular bundles on both the raphal and antiraphal sides of three seeds. E, S170230; longitudinal orthoslice (xz1300) of the four seeds in B, perpendicular to the dorsiventral plane, showing the massive endotesta and the weakly developed mesotesta; note ovular vascular bundles on both the raphal and antiraphal sides of the seeds. F, G, S153509. F, Longitudinal orthoslice (yz0433) of four tightly coherent seeds, perpendicular to the dorsiventral plane, showing the massive endotesta and the weakly developed mesotesta; 
thicker than endotesta. Mesotesta two cell layers thick; cells cubic; cells of inner cell layer with evenly thick cell walls; cells of outer cell layer thin-walled, not undulate. Endoreticulate infillings of endotesta cells dense. Endotesta without interspersed cavities. Ovular vascular bundle between mesotesta and endotesta. Testa surrounding micropyle slightly swollen. Outer epidermis of tegmen with slightly elongate, thin-walled cells.

Dimensions. Length of fruit: $0.8-1.1 \mathrm{~mm}$; width of fruit (dorsiventrally): 0.9-1.4 mm.

Holotype designated here. S174492 (Vale de Água 300; illustrated here in figs. 19, 20A-20C).

Plant Fossil Names Registry. PFN000133 (for new species).

Paratypes designated here. S175184 (Vale de Água sample 19), S175185 (Vale de Água sample 141), S175186 (Vale de Água sample 265), S175187 (Vale de Água sample 300), S175192(Vale deÁgua sample 328), S175191(Vale de Água sample 408).

Repository. Palaeobotanical Collections, Department of Palaeobiology, Swedish Museum of Natural History, Stockholm, Sweden (S).

Type locality. Vale de Água (lat. $39^{\circ} 37^{\prime} 15^{\prime \prime} \mathrm{N}$, long. $\left.08^{\circ} 51^{\prime} 30^{\prime \prime} \mathrm{W}\right)$.

Type stratum and age. Early Cretaceous (late Aptian-early Albian; basal part of the Figueira da Foz Formation).

Occurrence in Portugal. Recorded only from the Vale de Água locality.

Description and remarks. The species is based on 24 specimens, of which three were studied using SRXTM (S174492, S175157, S175158). Most specimens are abraded with only fragments of the fruit wall remaining.

The fruits are broadly elliptical in lateral view and ovate to circular in transverse section (figs. 19A, 19B, 19D-19G, 20A, 20C). None of the specimens have the stigmatic area or pollen preserved.

Each fruit contains two seeds arranged above each other; rarely there is only a single seed (figs. 19A, 19B, 20A, 20B). Both seeds of a pair appear to have developed to maturity (figs. 19D-19G, 20A).

Seeds are similar in general organization to the type species. The micropyle is seen in the outer integument as a small, rounded opening bordered by a faint swelling of the testa (fig. 19A-19C).

The ovular vascular bundle is between the mesotesta and the endotesta (figs. 19D, 19E, 20C). In all seeds studied using SRXTM, the bundle on the raphal side of the seed (figs. 19D, $20 \mathrm{C}$ ) is much more prominent than it is on the antiraphal side (fig. 19E).

The testa is thick, mesotestal-endotestal, with the mesotesta thicker than the endotesta over most of the seed (figs. 19D$19 G, 20 A-20 C)$. In the contact area between the two seeds, the mesotesta and endotesta are of approximately the same thickness (fig. 19G, 20B). The mesotesta is two cell layers thick and consists of cubic sclerenchyma cells with scattered perforations (figs. 19D-19G, 20A-20D). The cell walls of the inner mesotesta are thick, while those of the outer mesotesta are thinner and break easily, resulting in an uneven and finely reticulate pattern on the outer surface of the seeds (fig. 19A$19 G)$. The anticlinal cell walls of the mesotesta are not folded (fig. 20D). The endotesta is several cell layers thick, composed of small polygonal and equiaxial cells with endoreticulate infillings and a single central lumen (fig. 20D). Close to the ovular vascular bundle, the infillings in the endotestal cells are only weakly developed (fig. 20C). The tegmen is thin, with cells of the outer epidermis slightly elongate and radiating from the chalaza to the micropyle (fig. 19G). The surface of the seed cavity is smooth.

Nutritive tissue is cellular (figs. 19F, 20A, 20B). An empty space in the micropylar end of the nutritive tissue indicates that the embryo was tiny (fig. 20A, 20B).

\section{Riaselis E.M.Friis, P.R.Crane \& K.R.Pedersen gen. nov.}

Derivation of generic name. Riaselis is an anagram of Serialis to indicate close similarity between the two genera.

Generic diagnosis. Fruit/fruitlet indehiscent, with a thin wall; one seeded. Style lacking. Inner layer of fruit wall with narrow, elongate fibers. Stigmatic area restricted. Seed small, anatropous, bitegmic, and mesotestal-endotestal, with thick outer integument (testa) and thin inner integument (tegmen). Mesotesta one cell layer thick, composed of larger sclerenchyma cells. Endotesta several cell layers thick, composed of small polygonal cells with endoreticulate infillings. Seed surface coarsely rugulate. Micropyle formed from inner integument. Hilum and micropyle close together, not separated by testal tissue, resulting in a wide transversely oriented micropylar-hilar opening in the testa. Ovular vascular bundle continuing beyond the chalaza on the antiraphal side of the seed to the micropyle. Embryo tiny. Endosperm cellular, not-ruminate.

Distinguishing features for the genus. The fossil fruits and seeds included in Riaselis are similar to seeds of Serialis in their mesotestal-endotestal seed coat organization and the unusual extension of the ovular vascular bundle on the antiraphal side of the seed from the chalaza to the micropyle. However, the consistently uniovulate nature of the fruits/fruitlets is an important distinguishing feature for Riaselis, as is also their coarsely rugulate surface.

Type species designated here. Riaselis rugosa gen. et sp. nov. Plant Fossil Names Registry. PFN000134 (for new genus).

Riaselis rugosa E.M.Friis, P.R.Crane \& K.R.Pedersen gen. et sp. nov. (Figs. 21, 22)

Etymology. From the rugose surface of the seed (Latin rugosus [wrinkled]).

Specific diagnosis. As for the genus.

Dimensions. Length of fruit: 1.1-2.2 mm; width of fruit (dorsiventrally): 0.7-1.2 $\mathrm{mm}$.

Holotype designated here. S174029 (Famalicão 25; illustrated here in figs. $21 A-21 E, 22 A-22 C$ ).

Plant Fossil Names Registry. PFN000135 (for new species).

note ovular vascular bundles and remains of nutritive tissue (nu) in one of the central seeds. G, Transverse orthoslice (xy0183) close to the apex of the upper seed through cells of the endotesta showing the polygonal cell outlines, the small lumen, and the dense endoreticulate infillings of fibrous sclerified material. H, Transverse orthoslice (xy0762) through seed coat showing cells of the endotesta and the mesotesta; note that the cells of the mesotesta are thin walled with wavy cell outlines. Scale bars $=250 \mu \mathrm{m}(A, B, D-F), 125 \mu \mathrm{m}(C, G, H)$. 

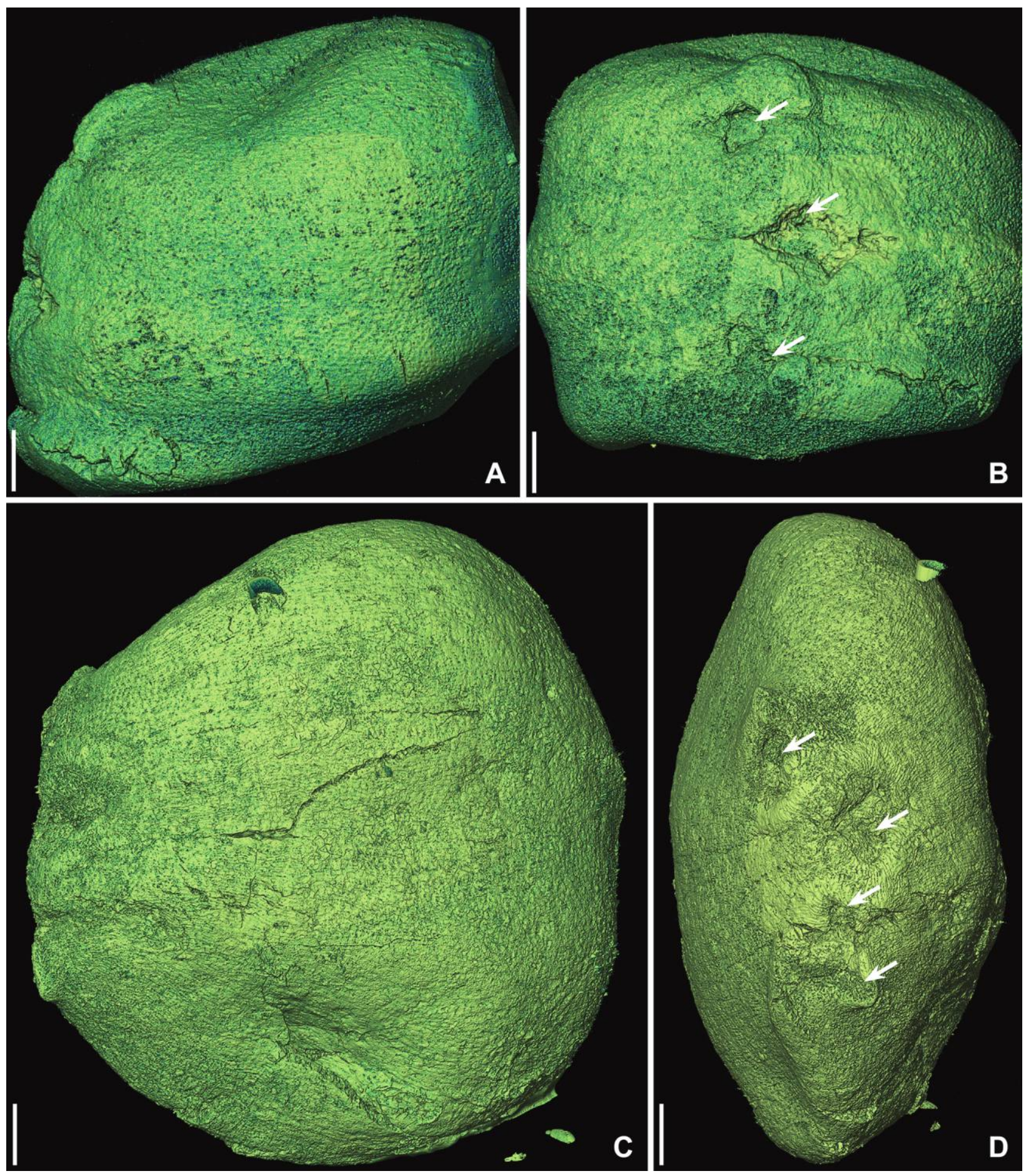

Fig. 15 Synchrotron radiation X-ray tomographic microscopy images (volume renderings) of seeds of Serialis grossa sp. nov. from the Early Cretaceous Famalicão locality, Portugal (Famalicão sample 25), showing tightly coherent seeds with very indistinct boundaries between adjacent seeds; note the alternating micropyles (arrows) and associated prominent swellings. $A, B, \mathrm{~S} 174813$; lateral $(A)$ and ventral $(B)$ view of a tightly coherent group of three seeds. $C, D$, Holotype, $\mathrm{S} 175150$; lateral $(C)$ and ventral $(D)$ view of a tightly coherent group of four seeds. Scale bars $=$ $250 \mu \mathrm{m}$. 

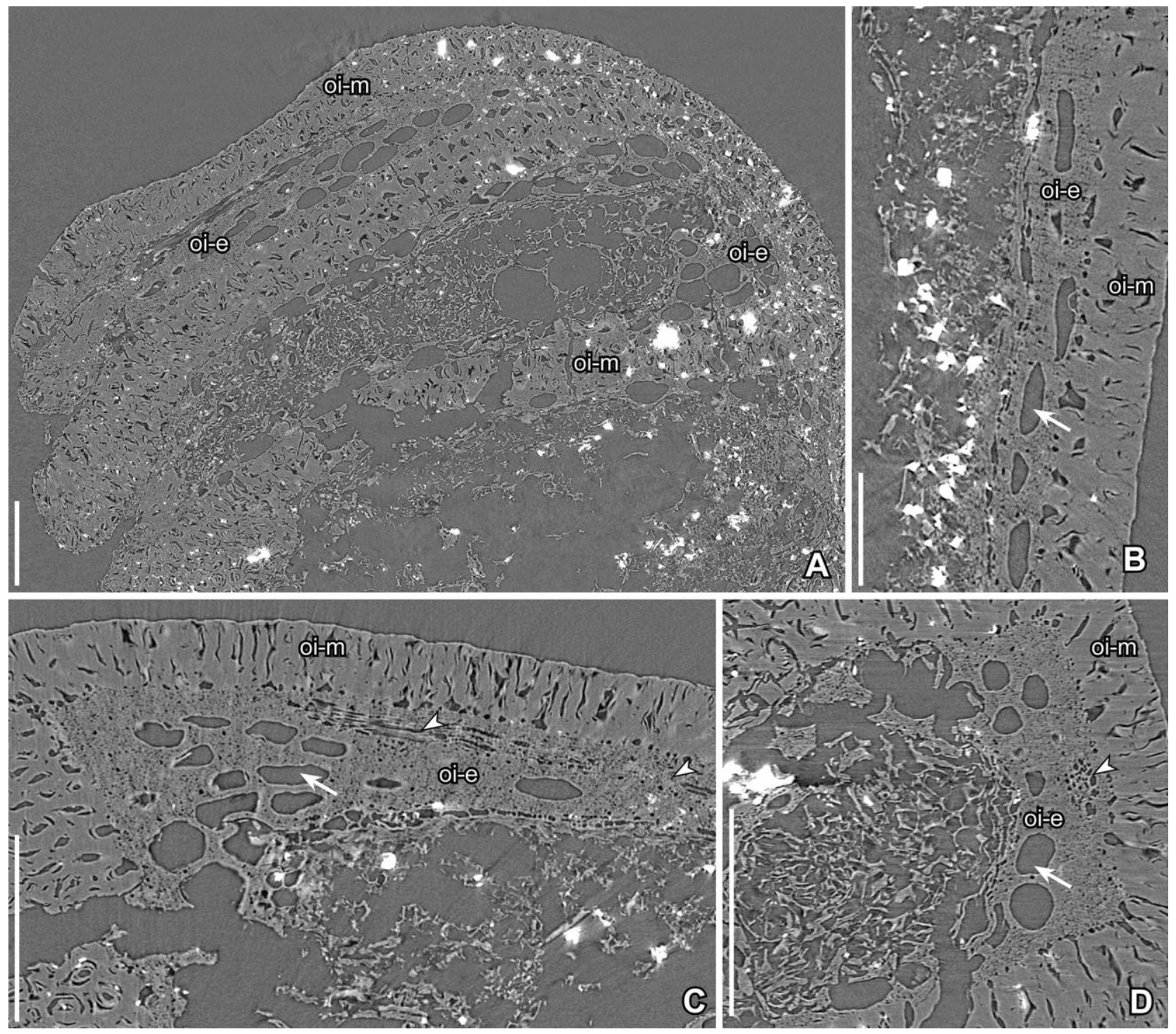

Fig. 16 Synchrotron radiation X-ray tomographic microscopy images (orthoslices) of seeds of Serialis grossa sp. nov. from the Early Cretaceous Famalicão locality, Portugal (Famalicão sample 25), showing the extensive development of thick-walled cells comprising the mesotesta (oi-m) and the thick-walled cells of the endotesta (oi-e) with characteristic elongated interspersed cavities (possible oil cells, arrows). A-D, Holotype, S175150; longitudinal ( $A$, yz1597; $C$, xz1926) and transverse ( $B$, xy1850; $D$, xz1926); note the densely infilled cells of the endotesta and the ovular vascular bundle extending in the endotesta (arrowheads). Scale bars $=250 \mu \mathrm{m}(A, C, D), 125 \mu \mathrm{m}(B)$.

Paratypes designated here. S107711-S107717, S170241, S170242, S174030, S174422, S174825, S175196-S175198 (Famalicão sample 25).

Repository. Palaeobotanical Collections, Department of Palaeobiology, Swedish Museum of Natural History, Stockholm, Sweden (S).

Type locality. Famalicão (lat. $39^{\circ} 42^{\prime} 16^{\prime \prime} \mathrm{N}$, long. $\left.8^{\circ} 46^{\prime} 12^{\prime \prime} \mathrm{W}\right)$.

Type stratum and age. Below the Figueira da Foz Formation; Early Cretaceous (late Aptian-early Albian or older).

Occurrence in Portugal. Most specimens are from the Famalicão locality (type locality), but there are also a few specimens from the Arazede and Vale de Água localities.

Description and remarks. The genus and species are based on about 25 specimens from the Famalicão locality. A few specimens have a well-preserved fruit wall, but most are iso- lated seeds with only scattered remains of fruit wall coherent to the seed surface. Four specimens were studied using SRXTM (S170242, S174030, S174422, S174825).

The fruit is obovate to elliptical in lateral view with a pointed base, a rounded or pointed apex, and an almost circular transverse section (figs. $21 A-21 E, 22 A-22 C$ ). The stigmatic area is restricted (fig. $21 F, 21 H$ ). Clusters of pollen grains have been observed on the stigmatic surface of one specimen (fig. $21 \mathrm{H}$, $21 I$ ). The pollen grains are small, about $15 \mu \mathrm{m}$ in diameter, semitectate-reticulate, and apparently monocolpate (fig. 21I$21 J)$. The outer epidermis of the fruit wall consists of small cells with polygonal and equiaxial facets. Small scattered holes in the epidermis are interpreted as trichome bases (fig. $21 H$ ). The fruit wall is thin and consists of small, thinwalled cells. The inner epidermis of the fruit wall consists of 

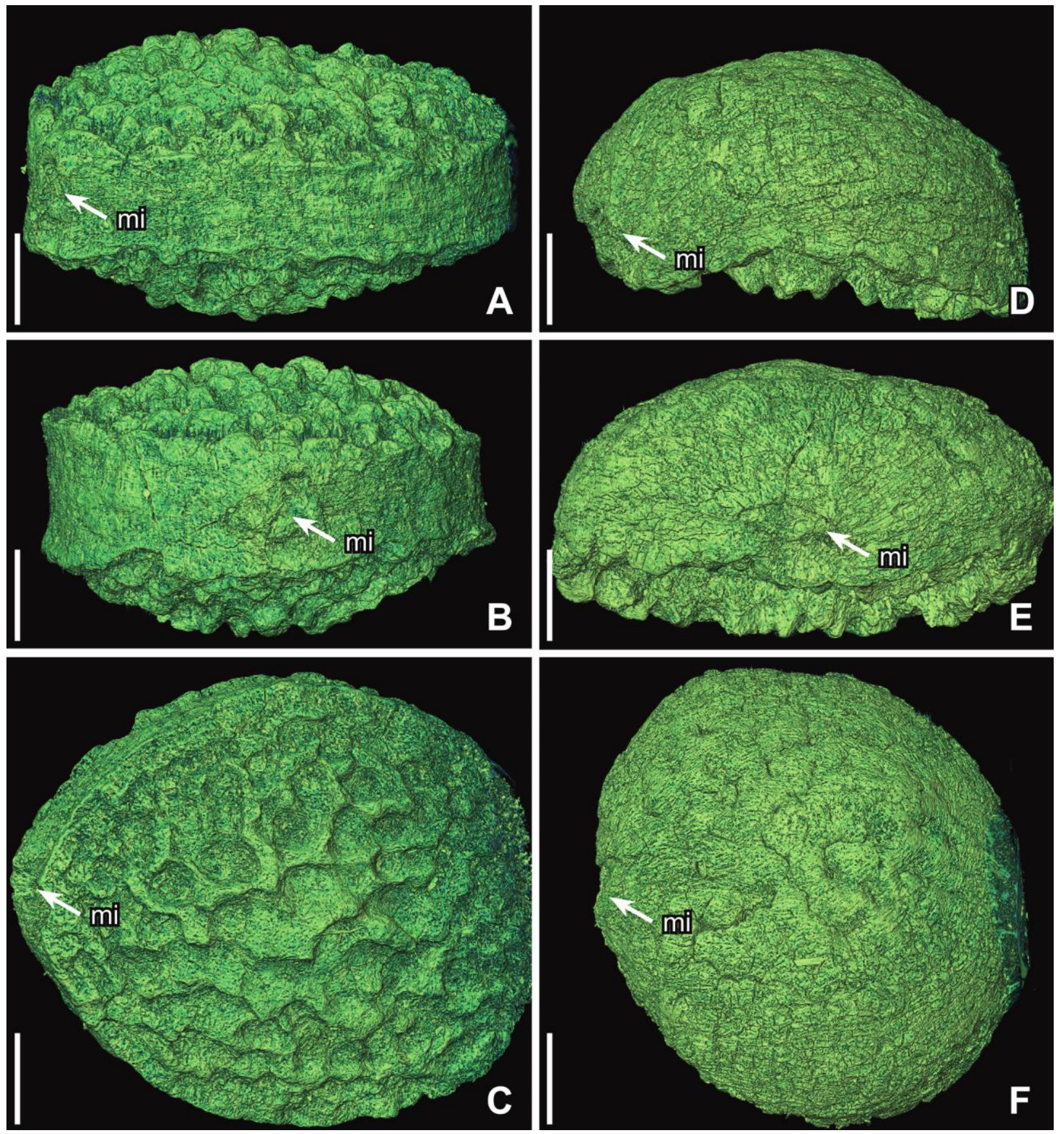

Fig. 17 Synchrotron radiation X-ray tomographic microscopy volume renderings of seeds of Serialis undata sp. nov. from the Early Cretaceous Famalicão locality, Portugal (Famalicão sample 25), showing separated seeds from a group of several coherent seeds; note the faintly rugulate outer surface, the strongly wavy/rugulate contact faces from two seeds, and the micropylar opening (mi) in the testa. $A-C$, Holotype, S175147; lateral $(A)$, ventral $(B)$, and apical $(C)$ view of a median seed. $D-F, S 175148$; lateral $(D)$, ventral $(E)$, and apical $(F)$ view of a terminal seed; note the superficial striations on the outer surface of the seed created by the cells of the inner fruit epidermis. Scale bars $=250 \mu \mathrm{m}$.

narrow, elongate cells, which are seen as fine longitudinal striations on the seed surface where the fruit wall is missing (fig. 21A, 21D).

The fruit is always one seeded, and the seed is anatropous, bitegmic, and mesotestal-endotestal. The micropyle and hilum are close together. The micropyle is formed from the inner integ- ument. There is no exotestal and mesotestal tissue between the micropyle and the hilum. The micropylar opening in the outer integument is usually covered by remains of fruit wall and stigma.

The ovular vascular bundle is in the testa between the endotesta and the mesotesta. It extends from the hilum close to 

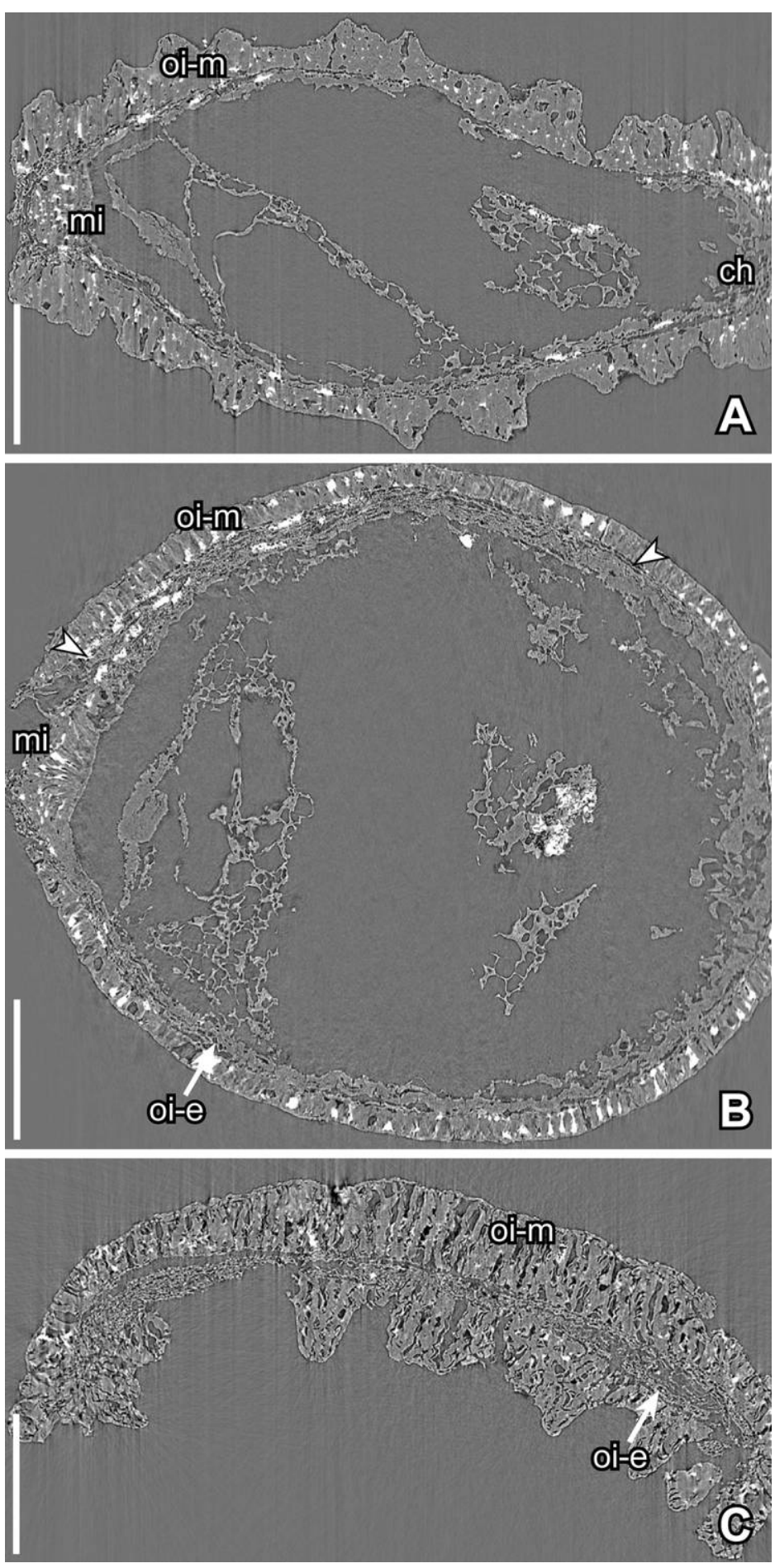

Fig. 18 Synchrotron radiation X-ray tomographic microscopy images (orthoslices) of seeds of Serialis undata sp. nov. from the Early Cretaceous Famalicão locality, Portugal (Famalicão sample 25), showing strongly wavy/rugulate contact faces formed by the uneven heights of the mesotesta cells (oi-m); note that the endotesta (oi-e) is thin and that the endoreticulate infillings are not well developed. A, B, Holotype, S175147; longitudinal $(A, \mathrm{xy} 1004)$ and transverse $(B, \mathrm{yz} 0630)$ orthoslice through a median seed of a seed group showing the micropylar area (mi) and the chalaza (ch). C, S175148; longitudinal orthoslice (xy0795) through a collapsed seed from the end of a seed group showing one strongly wavy/ rugulate contact face and one faintly rugulate noncontact face; note the well-developed mesotesta and the compressed endotesta. Scale bars = $250 \mu \mathrm{m}$.

This content downloaded from 152.088.042.152 on April 16, 2019 05:45:57 AM 

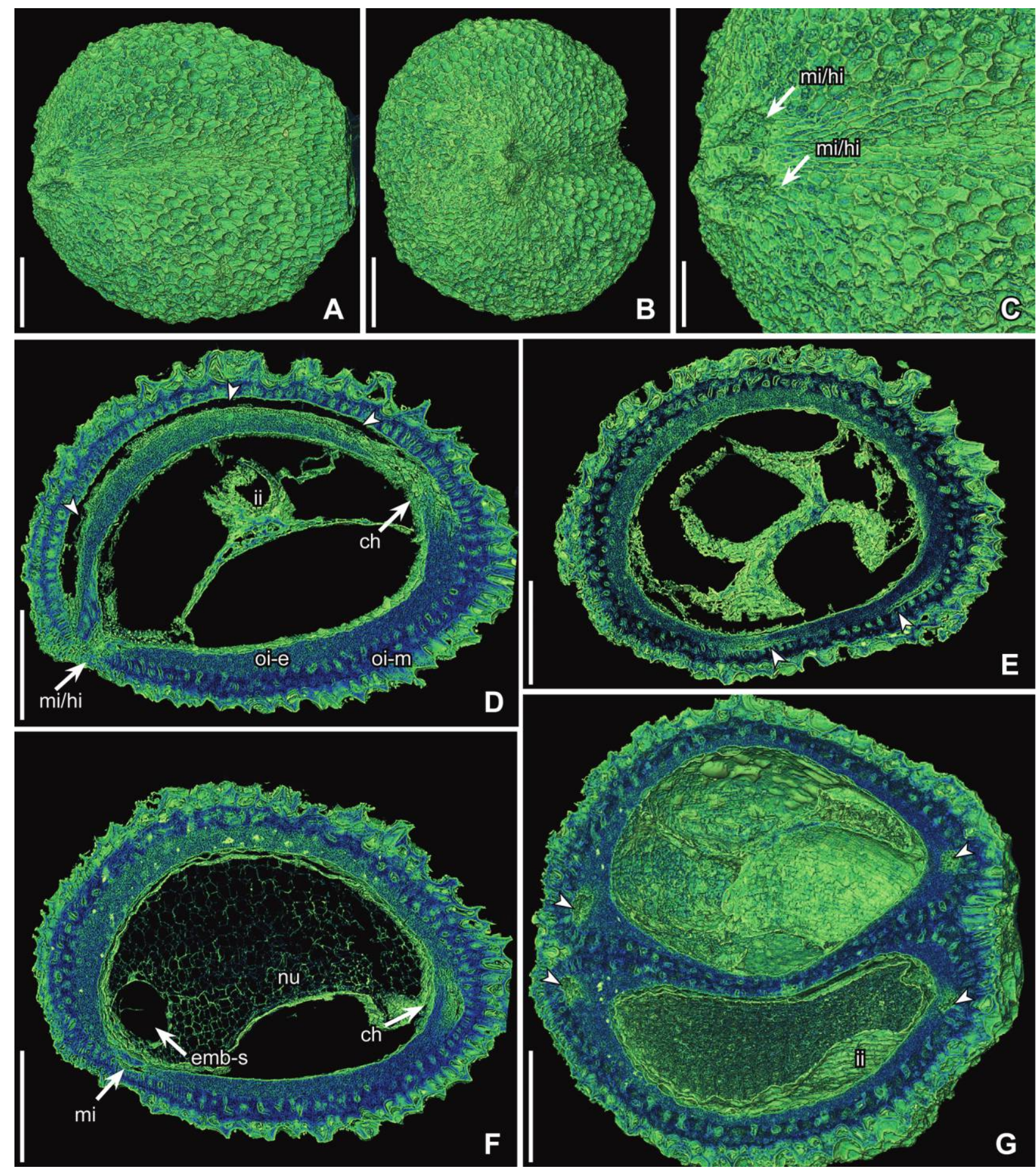

Fig. 19 Synchrotron radiation X-ray tomographic microscopy images (volume renderings) of seeds of Serialis reticulata sp. nov. from the Early Cretaceous Vale de Água locality, Portugal (Vale de Água sample 300), showing two tightly coherent seeds, finely reticulate seed surface, and small, rounded micropylar/hilar openings (mi/hi) in the testa; note the well-developed mesotesta (oi-m) and endotesta (oi-e) and the distinct ovular vascular bundle (arrowheads) extending between the mesotesta (oi-m) and the endotesta (oi-e). A-G, Holotype, S174492. A-C, Lateral $(A, C)$ and ventral $(B)$ view of a pair of tightly coherent reticulate seeds; note the indistinct boundary between adjacent seeds and the two adjacent micropylar/hilar areas. $D, E$, Transverse section $(D$, cut between orthoslices xz0965 and xz0995; $E$, cut between orthoslices xz1190 and xz1220) at two different levels through one seed of a seed pair showing the micropylar/hilar area and the chalaza (ch), the mesotesta (and possible exotesta), the endotesta, and the thin tegmen (ii); note that the ovular bundle is more prominent on the raphal side of the seed $(D)$ than on the antiraphal side $(E)$ opposite the chalaza. F, Transverse section (cut between orthoslices xz0530 and xz0560) through the second seed of the seed pair of showing the micropyle, the reticulate seed surface, and the endotesta; note the well-developed cellular nutritive tissue (nu) inside the tegmen and the small cavity adjacent to the micropyle indicating the former position of the embryo (emb-s). G, Longitudinal section (cut at orthoslice yz0622) perpendicular to the dorsiventral plane through the seed pair showing the reticulate seed surface, the well-developed mesotesta, and the remains of nutritive tissue inside the tegmen; note the ovular vascular bundle along both margins of each seed. Scale bars = $250 \mu \mathrm{m}(A, B, D-G), 125 \mu \mathrm{m}(C)$. 

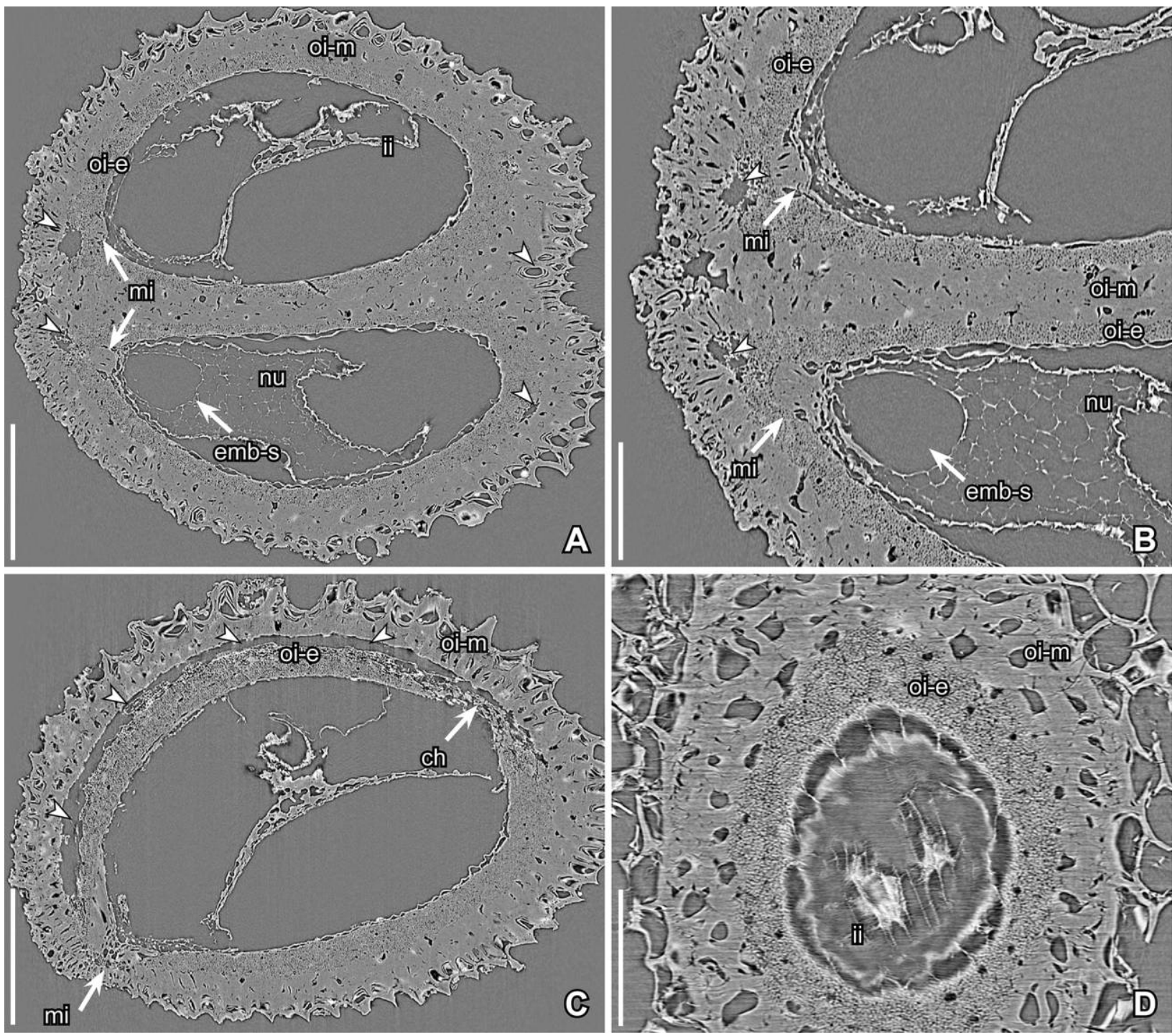

Fig. 20 Synchrotron radiation X-ray tomographic microscopy images (orthoslices) of seeds of Serialis reticulata gen. et sp. nov. from the Early Cretaceous Vale de Água locality, Portugal, showing the reticulate seed surface, the well-developed mesotesta (oi-m), the endotesta (oi-e), remains of the nutritive tissue (nu), and the cavity from the tiny embryo (emb-s) inside the tegmen (ii); note the ovular vascular bundle (arrowheads) along both margins of each seed. A-C, Holotype, S174492 (Vale de Água sample 300). A, Longitudinal orthoslice (yz0422) through a pair of closely coherent seeds parallel to the dorsiventral plane. B, Longitudinal orthoslice (yz0388) from a closely coherent pair of seeds showing details of the seed coat and ovular vascular bundles that correspond to the two seeds; note the position of the micropyle (mi) and the cellular nutritive tissue (nu) enclosing a cavity indicating the former position of the embryo. C, Transverse orthoslice (xz0995) through the seed showing the micropylar/hilar area opposite the chalaza (ch) and the prominent ovular vascular bundle extending in the seed coat between the mesotesta and the endotesta. D, S175157 (Vale de Água sample 19); longitudinal (tangential) section (cut at yz0257) through the seed coat of one of the seeds in $A$ showing the transition from the cells of the mesotesta to the cells of the endotesta that surround the tegmen and that are filled with fibrous sclerified material (ii). Scale bars $=250 \mu \mathrm{m}(A, C), 125 \mu \mathrm{m}(B, D)$.

the micropyle, to the chalaza at the other end of the seed, and then from the chalaza on the antiraphal side of the seed to the level of the micropyle (figs. $21 B, 21 C, 22 A-22 C$ ).

The testa is thick, with the mesotesta and endotesta approximately the same thickness over most of the seed (figs. $21 B$, $21 C, 21 E, 21 F, 22)$. The mesotesta is one cell layer thick and consists of almost cubic sclerenchyma cells. The cell walls are thick, with scattered perforations and a smooth inner surface (fig. 22E); the anticlinal walls are of almost equal thick- ness from the inside to the outside and are unfolded (fig. 22D, $22 E$ ). The endotesta is several cell layers thick and is composed of small polygonal and equiaxial cells with dense, porous infillings and a small central lumen (fig. 22E). The tegmen is thin, with the outer epidermis composed of narrow, elongate cells (fig. 21G). The surface of the seed cavity is smooth (figs. 21B, 21C, 21E, 22A-22C).

A tiny embryo surrounded by cellular nutritive tissue was observed in one specimen (fig. 22F). 

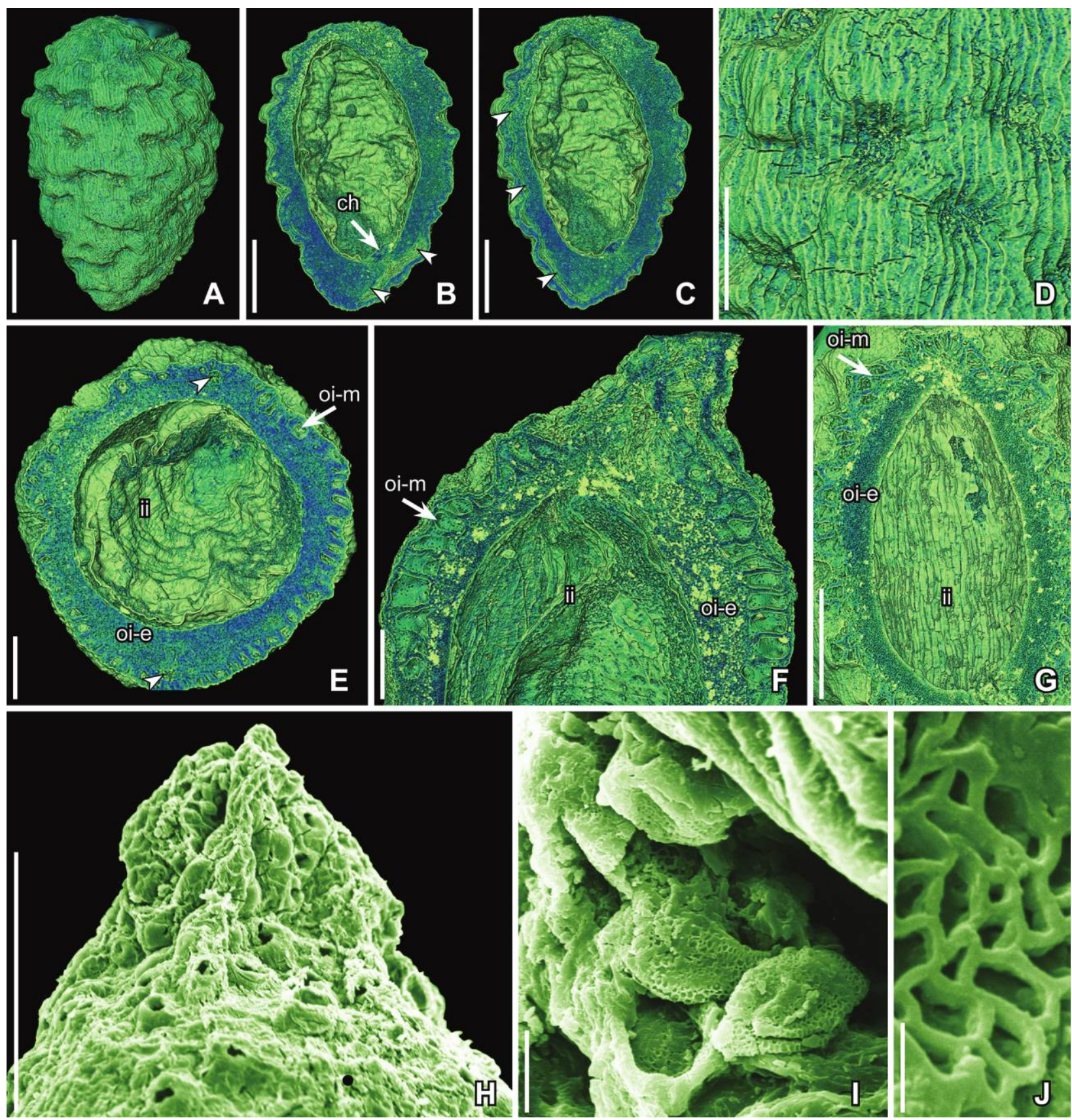

Fig. 21 Synchrotron radiation X-ray tomographic microscopy images (volume renderings, $A-G$ ) and SEM images $(H-J)$ of a fruit and seeds of Riaselis rugosa gen. et sp. nov. from the Early Cretaceous Famalicão locality, Portugal (Famalicão sample 25), showing the coarsely rugulate surface of seeds created by the irregular development of cells of the mesotesta, the slightly pointed stigmatic area, and pollen; note the welldeveloped mesotesta (oi-m) and endotesta (oi-e), the thin tegmen (ii), and the ovular vascular bundle (arrowheads) extending in the testa between the mesotesta and the endotesta. A-E, Holotype, $\mathrm{S} 174029$. A, Lateral view of seed showing irregular and finely striate surface. $B, C$, Longitudinal section at two different levels $(B$, cut at orthoslice yz0572; $C$, cut at orthoslice yz0606) through the seed in $A$ showing the rugulate surface of the mesotesta (individual cells poorly preserved); note the position of the chalaza (ch) and the course of the ovular vascular bundle on both sides of the chalaza. $D$, Detail of rugulate seed surface showing a finely striate pattern created by inner epidermis cells of the fruit wall. $E$, Transverse section (cut at orthoslice xy0824) through the fruit showing the mesotesta and the massive endotesta; note the course of the ovular vascular bundle between the mesotesta and the endotesta and the thin cells of the tegmen. F, S174030; longitudinal section (cut at orthoslice yz0617) through a fruit apex showing the stigmatic area, expanded cells of the mesotesta, and the massive endotesta. G, S170241; longitudinal (tangential) section (cut at orthoslice yz0937) through a seed showing the junction between the mesotesta, the endotesta, and the tegmen. $H-J$, S107711; stigmatic area at fruit apex showing probable trichome bases $(\mathrm{H})$ and adhering pollen grains $(I)$ with a semitectate reticulate pollen wall $(J)$. Scale bars $=250 \mu \mathrm{m}(A-C, G, H), 125 \mu \mathrm{m}(D-F), 10 \mu \mathrm{m}(I), 1 \mu \mathrm{m}(J)$. 

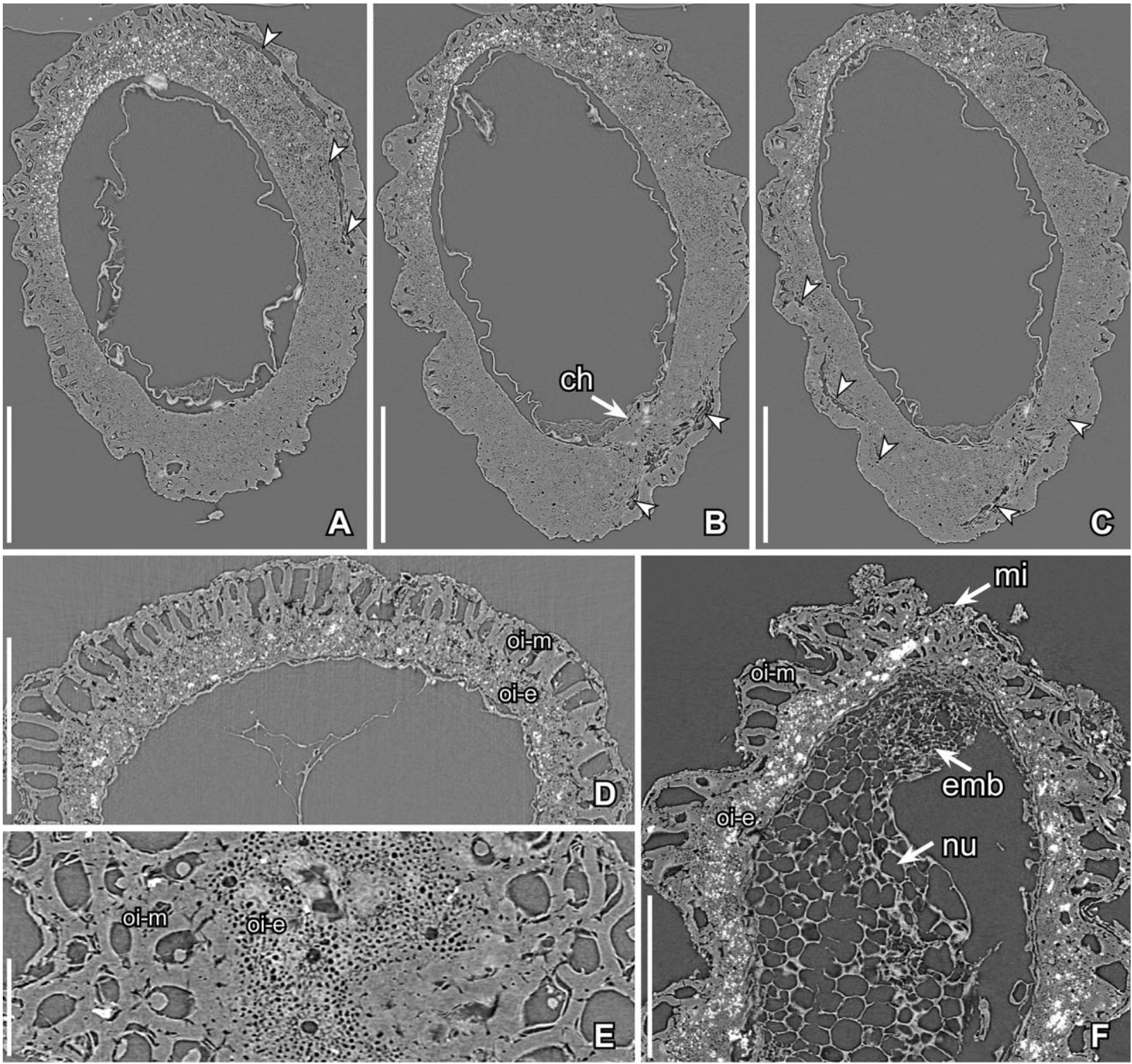

Fig. 22 Synchrotron radiation X-ray tomographic microscopy images (orthoslices) of seeds of Riaselis rugosa gen. et sp. nov. from the Early Cretaceous Famalicão locality, Portugal (Famalicão sample 25), showing the rugose surface formed by the irregular development of cells of the mesotesta (oi-m) and the massive endotesta (oi-e); note the course of the ovular vascular bundle between the mesotesta and the endotesta (arrowheads) and on both sides of the chalaza (ch). A-C, Holotype, S174029; longitudinal orthoslices at three different levels $(A$, yz0442; $B$, yz0554; $C$, yz0580) through the seed rugose surface, the mesotesta (individual cells poorly preserved), and the massive endotesta and ovular vascular bundle on both sides of the chalaza. $D, \mathrm{~S} 174825$; transverse orthoslice (xy1000) of seed showing large cells of the mesotesta and the massive endotesta. E, S174422; longitudinal (tangential) orthoslice (yz0174) through the seed coat showing the evenly thickened and finely pitted cell walls of the mesotesta and the porous infilling of the endotestal cells. F, S170242; longitudinal orthoslice (yz0709) showing the rugosities formed by the cells of the mesotesta, the massive endotesta, and the micropyle (mi); note the small, poorly developed embryo (emb) adjacent to the micropyle, with its associated nutritive tissue (nu). Scale bars $=250 \mu \mathrm{m}(A-D, F), 50 \mu \mathrm{m}(E)$.

\section{Discussion}

Distinguishing Features of the New Fossil Taxa

The fossils described here belong to a group of angiosperm fruits and seeds that are abundant in some Early Cretaceous mesofossil floras from Portugal. They are particularly common in the Famalicão mesofossil flora, where more than 2600 specimens have been isolated from a relatively small (about $1 \mathrm{~kg}$ ) sample. The nine species of Serialis, together with Riaselis rugosa, illustrate the morphological and anatomical diversity in the group, but the group also includes many unassigned specimens. Even though the fruit wall is not preserved in all species, it is reason- 
able to infer that all of these seeds were produced in indehiscent, thin-walled, and unilocular fruiting units that developed from a single carpel. The fruiting units are always found isolated and are never attached to other structures. Because of the abundance of these isolated carpels, it is reasonable to infer that they were derived from monocarpellate flowers, and we refer to these units as fruits. However, the possibility that they were derived from apocarpous, multiparted gynoecia cannot be ruled out. The thin-walled parenchyma cells of the fruit wall suggest that the fruits were fleshy. None of the specimens shows any indication of a style, and the stigmatic area was sessile.

Fruits of Riaselis are always one seeded, and the seeds are strongly rugulate. Currently only one species, $R$. rugosa, is recognized. Fruits of all species of Serialis have two to six seeds that are borne in two rows along the ventral suture; only in rare cases is just a single seed developed. The seeds are tightly coherent and were clearly dispersed as a unit. The tight coherence of the seeds indicates that the seeds were probably united by postgenital fusion. Features that distinguish the different species of Serialis relate mainly to the nature of the stigma, the number of seeds per fruit, and details of the seed coat (table 1). Although differences in seed coat structure among the species of Serialis are considerable, we group them together in a single genus based on their same general organization, but the limits of the genus may need to be revised if other parts of the plants that produced these seeds are discovered.

\section{Systematic Affinity of Serialis and Riaselis}

The characteristic combination of features seen in the fossil seeds of Serialis is unusual. The key features are unilocular fruits (or fruiting units from an apocarpous gynoecium) with several anatropous, bitegmic, and mesotestal-endotestal seeds in which the micropyle is formed from the inner integument; hilum and micropyle not separated by exotestal-mesotestal tissue; and ovular vascular bundle extended in the testa from the chalazal to the micropyle on the antiraphal side of the seed (postchalazal strand). Endoreticulate infillings of the endotesta cells are also characteristic of the fossil seeds. Among extant angiosperms, fruits and seeds with comparable organization occur only in Austrobaileya (Austrobaileyaceae) and certain Magnoliales, but the fossil seeds differ from those of all living species and cannot be placed in any of the families established based on extant taxa.

Fruits of Austrobaileya are derived from an apocarpous gynoecium, and the resulting fruitlets are berries each containing several seeds. Seeds of Austrobaileya lack a well-developed endotesta, and the endotesta cells do not have endoreticulate infillings. In addition, in Austrobaileya the mesotesta is several cell layers thick and consists of polygonal and almost equiaxial cells with relatively thin sclerotic cell walls. Seeds of Austrobaileya also differ from the fossils in having an extended chalaza (perichalazal) and also in being distinctly ruminate, with the ruminations caused by uneven thickenings of the tanniferous exotesta (Yamada et al. 2003). The micropyle in seeds of Austrobaileya may be formed by the inner integument alone or more commonly by both integuments (Endress 1980, 1993).

Extant Magnoliales comprise six families. Based on combined molecular and morphological data, Myristicaceae are resolved as sister to a clade comprising all other families, within which Magnoliaceae are sister to Himantandraceae-Degeneriaceae plus
Eupomatiaceae-Annonaceae (Doyle and Endress 2000). Apocarpous fruits consisting of several fruitlets occur in Magnoliaceae, Himantandraceae, and Annonaceae. Fruits of Myristicaceae and Degeneriaceae are unicarpellate, while the fruit in Eupomatiaceae is formed from a syncarpous ovary. The number of seeds per carpel varies from one (Myristicaceae, Himantandraceae) to several (Magnoliaceae, Degeneriaceae, Eupomatiaceae, Annonaceae). In fruits with several seeds, the seeds are borne in two rows along the ventral side, as in Serialis, but although often closely packed together, the seeds are never coherent in permanent units as in Serialis.

As in Serialis and Riaselis, in five of the six families of extant Magnoliales, the micropyle is formed by the inner integument. In Magnoliaceae, the micropyle is formed by both integuments (Corner 1976; Umeda et al. 1994; Igersheim and Endress 1997). A further similarity to the fossil seeds is that seeds of many extant Magnoliales have a significant extension of the ovular vascular bundle beyond the chalaza on the antiraphal side of the seed (postchalazal strand). Seeds of Eupomatiaceae are an exception in having an ovular vascular bundle that ends in the chalaza (Corner 1976; Igersheim and Endress 1997). Seeds of Eupomatiaceae also differ from the fossils in the presence of mesotestal fibers, an unspecialized endotesta, and a ruminate endosperm caused by uneven growth of the long mesotestal fibers (Corner 1976). Mesotestal fibers and a ruminate endosperm caused by their uneven growth also characterize seeds of extant Annonaceae. Seeds of Annonaceae also differ from seeds of Serialis and Riaselis in lacking a sclerified endotesta and in being perichalazal, with an extension of the chalaza in the median plane (Corner 1976).

Seeds of Myristicaceae differ from those of Serialis and Riaselis in several respects. In Myristicaceae, each fruitlet contains a single pachychalazal seed in which the chalaza is massively extended in all directions. The mesotesta is subaerenchymatic, and the endotesta consists of one layer of tall sclerified prismatic cells. Seeds of Myristicaceae also have a prominent aril, the ovular vasculature is branched, and the endosperm is ruminate as a result of lobes extending inward from the tegmen (Corner 1976). The only distinctive feature that links seeds of Myristicaceae with any of the fossils described here is the fibrous exotegmen, which occurs in Serialis communis but not in the other species of Serialis or in the genus Riaselis or any extant Magnoliales (Corner 1976).

An unextended (simple) chalaza, as seen in Serialis and Riaselis, occurs in Degeneriaceae, Eupomatiaceae, Himantandraceae, and Magnoliaceae (Corner 1976), although in seeds of Magnoliaceae the endotesta forms a tube, the heteropyle, around the chalaza. This distinctive feature is not seen in the fossils of any magnolialean taxa outside the Magnoliaceae. Galbulimima F.M.Bailey, the only genus of Himantandraceae, differs from Serialis in having single-seeded fruitlets and differs from both Serialis and Riaselis in having relatively large mesotestal seeds in which the endotesta is composed of two or three layers of unspecialized aerenchymatous parenchyma (Doweld and Shevyryova 1998).

Seeds of Magnoliaceae and Degeneriaceae are similar to seeds of Serialis and Riaselis in having endotestal cells with characteristic endoreticulate infillings of lignified fibrils. In seeds of Magnoliaceae, the endotesta cells are tall, palisade shaped, with one or more crystals. The mesotesta is also 


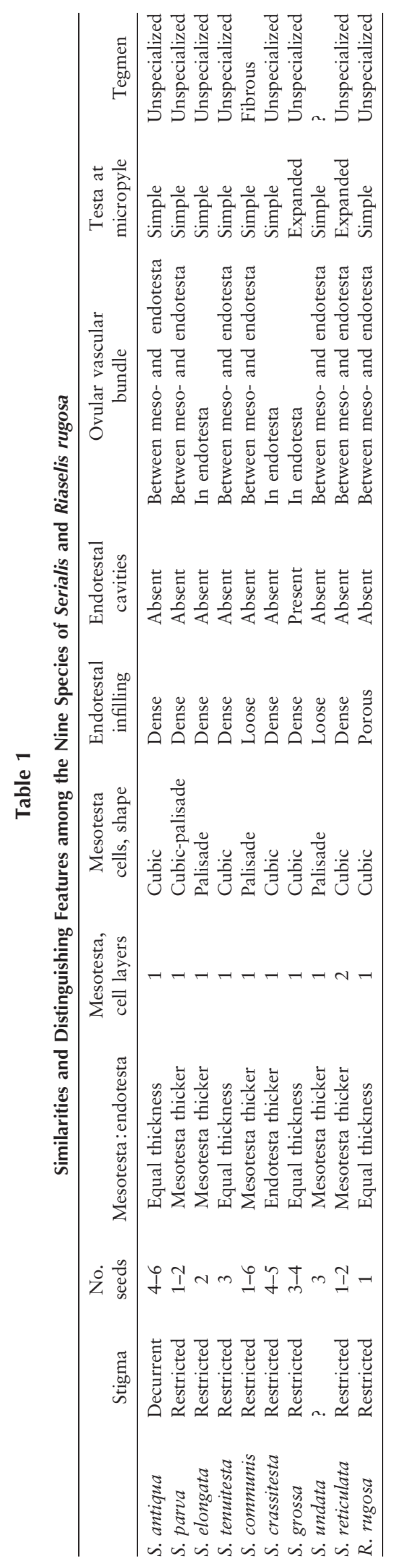

This content downloaded from 152.088.042.152 on April 16, 2019 05:45:57 AM 
sclerified, similar to the mesotesta in the fossil seeds, but the endotesta is two, rarely more, cell layers thick, and the cells are palisade shaped, with one or several crystals. In contrast, in Serialis and Riaselis the endotestal cells are small, polygonal, and isodiametric, apparently without a crystal or with a single central crystal.

In Degeneria I.Bailey \& A.C.Smith, the only genus of Degeneriaceae, the endotesta is composed of several layers of small equiaxial to palisade-shaped cells with the central cell lumen surrounded by dense, lignified fibrous matter, very similar to that in the endotesta cells of Serialis and Riaselis. However, in Degeneria the mesotesta is not sclerotic, and the seeds are distinctly ruminate, caused by ingrowth of the endotestal cells (Corner 1976).

The probable oil cells in the seed coat of Serialis grossa are similar to those in the seed coat of both Degeneriaceae and Magnoliaceae. They are especially like those in Magnoliaceae in being isolated and diffuse. Oil cells in the seed coat of Degeneria occur in clusters. However, S. grossa differs from both Degeneriaceae and Magnoliaceae in that the oil cells are in the endotesta rather than in the mesotesta or the exotesta.

The phylogenetic analysis supports the relationship of Serialis and Riaselis to Magnoliales inferred based on comparative morphology and anatomy (fig. 23), but there is also the possibility of a close relationship to Austrobaileya. When both Serialis and Riaselis are included in analyses with extant taxa, the two fossil genera form a clade with two equally parsimonious positions: sister to Magnoliaceae, Himantandraceae-Degeneriaceae plus Eupomatiaceae-Annonaceae or sister to LiriodendronMagnolioideae (both 1027 steps). A position as sister to Magnoliales, to Myristicaceae, or to Galbulimima-Degeneria plus Eupomatia-Annonaceae is only one step less parsimonious (1028 steps), as also is a position as sister to Austrobaileya. A position of Serialis plus Riaselis as sister to Austrobaileyales as a whole, or inside the order, is only two or three steps longer (1029-1030 steps). A position for Serialis and Riaselis inside the Magnoliaceae, or inside the Galbulimima-Degeneria plus Eupomatia-Annonaceae clade, is less parsimonious (10311032 steps). Positions outside Austrobaileyales and Magnoliales are also three to 11 steps longer (1030-1038 steps). When only Serialis is included, the pattern is almost the same, but there are three most parsimonious positions for Serialis: sister to Austrobaileya, sister to Magnoliaceae, Himantandraceae-Degeneriaceae plus Eupomatiaceae-Annonaceae, or sister to LiriodendronMagnolioideae (1026 steps).

Based on these comparisons and analyses, we think that Serialis and Riaselis can be placed in Magnoliales with reasonable certainty based on strong similarities in mesotestal and endotestal anatomy, but a close relationship between the two fossil taxa, and Austrobaileya is also possible.

Austrobaileya occupies a key position in current ideas of early angiosperm diversification. Currently, it is resolved as sister to other Austrobaileyales, a group that is sister to all living angiosperms except Amborella and Nymphaeales. In premolecular classifications, Austrobaileya was often placed among eumagnoliid angiosperms, either at the base of, or in, the Laurales (e.g., Bailey and Swamy 1949; Takhtajan 1969), more frequently in the Magnoliales (e.g., Cronquist 1981; Loconte and Stevenson 1991; Kubitzki 1993), or between Magnoliales and Laurales, but closer to Magnoliales than to Laurales (Endress
1980). Austrobaileya exhibits one of the most distinctive features of the fossil seeds, the extension of the ovular bundle in the testa beyond the chalaza (Endress 1980). The possibility that such an extended ovular vascular bundle is the basic condition, not only for seeds of all Magnoliales but perhaps also for seeds of Austrobaileyales and other groups of angiosperms, deserves further exploration. Its apparent loss in Chloranthaceae could be related to a change in ovule form, from the anatropous to orthotropous condition.

Also interesting is that in both Austrobaileya and Magnoliales, the extension of the ovular vascular bundle seems to correlate with the presence of ruminate endosperm, raising the possibility that an extension of the vascular bundle beyond the chalaza (the pachychalazal in Austrobaileya, the perichalazal in Annonaceae) is a requirement for the development of ruminations. Serialis and Riaselis lack ruminations, and, so far, ruminations have not been observed in any of the numerous Early Cretaceous seeds that we have investigated. We consider it unlikely that ruminations were lost in the fossil seeds. It is more likely that ruminations reflect the subsequent independent evolution of a seed protection mechanism in Myristicaceae and in the clade comprising Himantandraceae-Degeneriaceae plus Eupomatiaceae-Annonaceae. In Myristicaceae, the ruminations originate by growth of the tegmen and the chalaza, whereas in the Himantandraceae-Degeneriaceae plus EupomatiaceaeAnnonaceae clade, ruminations originate by growth of the testa. A deeper exploration of this and other interesting biological/ecological phenomena implied by patterns of character evolution among early-diverging angiosperm lineages will require an improved understanding of Serialis, Riaselis, and other relevant extinct diversity.

\section{Comparison with Other Fossil Fruits and Seeds}

Seeds comparable to those of Serialis that are also tightly coherent in rows occur outside of Portugal in similar mesofossil floras from eastern North America. Seeds from the Early Cretaceous (early-mid Albian) Kenilworth locality, Maryland (E. M. Friis, P. Crane, and K. R. Pedersen, unpublished data), differ in details of the seed coat and will be described as a separate genus of the Serialis-Riaselis complex. In addition, aggregations of seeds in rows similar to those of Serialis are also known from the Late Cretaceous (earliest Cenomanian) mesofossil flora of Mauldin Mountain, Maryland (dispersed seeds with probable magnolialean affinities in Crane and Herendeen 1996). It is possible that such seeds were also produced by Archaeanthus Dilcher \& P.R.Crane, from the earliest Late Cretaceous of central Kansas (Dilcher and Crane 1984), but the quality of preservation in compression fossils of Archaeanthus is not adequate for detailed comparison. So far, similar seed units have not been reported from younger floras from the Late Cretaceous or from the Cenozoic.

There is some resemblance between seeds of Serialis and Riaselis and seeds of Liriodendroidea Knobloch \& Mai from the Late Cretaceous of Germany, Kazakhstan, and eastern North America that have been assigned to the Magnoliaceae (Knobloch and Mai 1984; Frumin and Friis 1996, 1999). In this material, as also in the material from the Mauldin Mountain mesofossil flora, the fruiting units are comprised of several to many coherent seeds, but the seeds were not in permanent dispersal units and are most commonly encountered 
isolated. Seeds of Liriodendroidea are further distinguished from seeds of Serialis by the presence of a distinct heteropyle, the palisade-shaped crystalliferous cells of the endotesta, and the presence of distinct wings. Fruits and seeds of Litocarpon Delevoryas \& Mickle from the Late Cretaceous of British Columbia, Canada, also assigned to the Magnoliaceae, are also winged, unlike Serialis and Riaselis (Delevoryas and Mickle 1995).

There is an interesting superficial resemblance between twoseeded specimens of Serialis and seed pairs of Tanispermum E.M.Friis, P.R.Crane \& K.R.Pedersen from the Early Cretaceous (Barremian-Aptian to early-mid Albian) of Virginia and Maryland, but instead of a postchalazal strand, there is apparently a short extension of the ovular vascular bundle from the hilum to the micropyle. Further, seeds of Tanispermum are exotestal, and the orientation of the seeds is different. Also, while seed pairs of Tanispermum may have been dispersed together, the seeds were not permanently coherent as in Serialis (Friis et al. 2018d).

\section{Conclusion}

The fossil seeds assigned to Serialis and Riaselis are part of an extinct complex of early angiosperms that were diverse and common in the Early Cretaceous floras of Portugal. Similar fossils also occur in Early and mid-Cretaceous mesofloras from eastern North America (e.g., Kenilworth, Mauldin Mountain localities, Maryland), indicating that the group was also geographically widespread. While these fossils cannot be placed in any existing family of the Magnoliales, they probably represent extinct taxa that were among the early branching lineages in the order. Subsequently, from the mid-Cretaceous onward, there are several records of fossil plants that can be assigned to the stem or crown groups of extant families of Magnoliales with high confidence, including Archaeanthus Dilcher \& P.R.Crane from the earliest Late Cretaceous of central Kansas (Dilcher and Crane 1984) and Liriodendroidea and Litocarpon from slightly later in the Late Cretaceous (see above). Also from the Late Cretaceous are reports of Annonaceae, including the flowers of Futabanthus Mas.Takah., E.M.Friis, Uesugi, Yosh.Suzuki \& P.R.Crane from the Coniacian of Japan (Takahashi et al. 2008) and ruminate seeds of Anonaspermum Ball emend. Reid \& Chandler from the Maastrichtian of Africa (Chesters 1955; Monteillet and Lappartient 1981). By the Eocene, Annonaceae and Magnoliaceae were diverse (Collinson 1983; Friis et al. 2011), and unequivocal Myristicaceae had also differentiated (Doyle et al. 2008).

Current knowledge of the fossil record suggests that the Late Cretaceous was a critical interval in the differentiation of modern families and genera of Magnoliales, with the differentiation of modern genera continuing through the Cenozoic. However, the earliest phases of magnolialean diversification appear to have occurred during the mid- to late Early Cretaceous. Based on the material described here, as well as other fossil material from the Early Cretaceous that remains to be studied, the initial diversification of Magnoliales and related groups included a great diversity of taxa that later became extinct. As these extinct taxa, including Serialis and Riaselis, come more clearly into view, it is very possible that they will influence, and perhaps overturn, currently accepted phylogenetic patterns near the base of the angiosperm tree, with important implications for hypotheses of character evolution during the earliest phases of angiosperm diversification.

\section{Acknowledgments}

We thank the Paul Scherrer Institute, Villigen, Switzerland, for provision of synchrotron radiation beam time at the TOMCAT Beamline X02DA of the Swiss Light Source (projects 20080872, 2010167, 20110963, 20130185, 20141047, 20160140, and 20171476). We are grateful to Federica Marone for her help at the beamline and Anna Lindström for help with the SRXTM analyses. We are also grateful to P. K. Endress and an anonymous reviewer for helpful comments on the manuscript. Support for this research was also obtained from the Swedish Research Council (Vetenskapsrådet 2014-5228 to E. M. Friis). P. R. Crane is grateful to the Oak Spring Garden Foundation for travel and other support.

\section{Literature Cited}

Bailey IW, BGL Swamy 1949 The morphology and relationships of Austrobaileya. J Arnold Arbor Harv Univ 30:211-226.

Chesters KIM 1955 Some plant remains from the Upper Cretaceous and Tertiary of West Africa. Ann Mag Nat Hist 12:498-503.

Collinson ME 1983 Fossil plants of the London Clay. Palaeontological Association, London.

Corner EJH 1976 The seeds of dicotyledons. Cambridge University Press, Cambridge.

Crane PR 1985 Phylogenetic analysis of seed plants and the origin of angiosperms. Ann Mo Bot Gard 72:716-793.

Crane PR, PS Herendeen 1996 Cretaceous floras containing angiosperm flowers and fruits from eastern North America. Rev Palaeobot Palynol 90:319-337.

Cronquist A 1981 An integrated system of classification of flowering plants. Columbia University Press, New York.

Delevoryas T, JE Mickle 1995 Upper Cretaceous magnoliaceous fruit from British Columbia. Am I Bot 82:763-768.
Dilcher DL, PR Crane 1984 Archaeanthus: an early angiosperm from the Cenomanian of the Western Interior of North America. Ann Mo Bot Gard 71:351-383.

Dinis JL, FP Oliveira, J Rey, IL Duarte 2010 Finding geological heritage: legal issues on private property and fieldwork: the case of outstanding early angiosperms (Barremian to Albian, Portugal). Geoheritage 2:77-90.

Dinis JL, J Rey, PP Cunha, P Callapez, R Pena Dos Reis 2008 Stratigraphy and allogenic controls of the western Portugal Cretaceous: an updated synthesis. Cretac Res 29:772-780.

Doweld AB, NA Shevyryova 1998 Carpology, seed anatomy and taxonomic relationships of Galbulimima (Himantandraceae). Ann Bot 81:337-347.

Doyle JA, PK Endress 2000 Morphological phylogenetic analysis of basal angiosperms: comparison and combination with molecular data. Int I Plant Sci 161(suppl):S121-S153.

2010 Integrating Early Cretaceous fossils into the phylogeny of living angiosperms: Magnoliidae and eudicots. I Syst Evol 48:1-35 
2014 Integrating Early Cretaceous fossils into the phylogeny of living angiosperms: ANITA lines and relatives of Chloranthaceae. Int I Plant Sci 175:555-600.

Doyle JA, CL Hotton, JV Ward 1990 Early Cretaceous tetrads, zonasulculate pollen, and Winteraceae. I. Taxonomy, morphology, and ultrastructure. Am I Bot 77:1544-1557.

Doyle JA, SR Manchester, H Sauquet 2008 A seed related to Myristicaceae in the Early Eocene of southern England. Syst Bot 33:636-646.

Endress PK 1980 The reproductive structures and systematic position of the Austrobaileyaceae. Bot Jahrb Syst 101:393-433.

1993 Austrobaileyaceae. Pages 138-140 in K Kubitzki, JG Rohwer, V Bittrich, eds. The families and genera of vascular plants. Vol II. Flowering plants: dicotyledons - magnoliid, hamamelid and caryophyllid families. Springer, Berlin.

Friis EM, PR Crane, KR Pedersen 2011 Early flowers and angiosperm evolution. Cambridge University Press, Cambridge.

2017 Saportanthus, an extinct genus of Laurales from the Early Cretaceous of Portugal. Int I Plant Sci 78:650-672.

- 2018a Extinct taxa of exotestal seeds close to Austrobaileyales and Nymphaeales from the Early Cretaceous of Portugal. Foss Impr 74:135-158.

$2018 b$ Fossil seeds with affinities to Austrobaileyales and Nymphaeales from the Early Cretaceous (early-middle Albian) of Virginia and Maryland, U.S.A: new evidence for extensive extinction near the base of the angiosperm tree. Pages 417-435 in M Krings, CJ Harper, NR Cúneo, GW Rothwell, eds. Transformative paleobotany: papers to commemorate the life and legacy of Thomas N. Taylor. Academic Press, London.

2018c Rightcania and Kvacekispermum: Early Cretaceous seeds from eastern North America and Portugal provide further evidence of the early chloranthoid diversification. Foss Impr 74:65-76.

- 2018d Tanispermum, a new genus of distinctive hemiorthotropous to hemi-anatropous angiosperm seeds from the Early Cretaceous of eastern North America. Am I Bot 105:1369-1388.

Friis EM, H Eklund, KR Pedersen, PR Crane 1994 Virginianthus calycanthoides gen. et sp. nov.: a calycanthaceous flower from the Potomac Group (Early Cretaceous) of eastern North America. Int I Plant Sci 155:772-785.

Friis EM, GW Grimm, MM Mendes, KR Pedersen 2015 Canrightiopsis, a new Early Cretaceous fossil with Clavatipollenites-type pollen bridge the gap between extinct Canrightia and extant Chloranthaceae. Grana 54:184-212.

Friis EM, F Marone, KR Pedersen, PR Crane, M Stampanoni 2014 Three-dimensional visualization of fossil flowers, fruits, seeds and other plant remains using synchrotron radiation X-ray tomographic microscopy (SRXTM): new insights into Cretaceous plant diversity. I Paleontol 88:684-701.

Friis EM, KR Pedersen 2011 Canrightia resinifera gen. et sp. nov., a new extinct angiosperm with Retimonocolpites-type pollen from the Early Cretaceous of Portugal: missing link in the eumagnoliid tree? Grana 50:3-29.

Friis EM, KR Pedersen, PR Crane 1995 Appomattoxia ancistrophora gen. et sp. nov., a new Early Cretaceous plant with similarities to Circaeaster and extant Magnoliidae. Am _ Bot 82:933-943.
2010 Cretaceous diversification of angiosperms in the western part of the Iberian Peninsula. Rev Palaeobot Palynol 162:341361.

Frumin S, EM Friis 1996 Liriodendroid seeds from the Late Cretaceous of Kazakhstan and North Carolina, USA. Rev Palaeobot Palynol 94:39-55.

1999 Magnoliid reproductive organs from the CenomanianTuronian of north-western Kazakhstan: Magnoliaceae and Illiciaceae. Plant Syst Evol 216:265-288.

Igersheim A, PK Endress 1997 Gynoecium diversity and systematics of the Magnoliales and winteroids. Bot I Linn Soc 124:213-271.

Knobloch E, DH Mai 1984 Neue Gattungen nach Früchten und Samen aus dem Cenoman bis Maastricht (Kreide) von Mitteleuropa. Feddes Repert 95:3-41.

Kubitzki K 1993 Introduction. Pages 1-12 in K Kubitzki, JG Rohwer, V Bittrich, eds. The families and genera of vascular plants. Vol II. Flowering plants: dicotyledons-magnoliid, hamamelid and caryophyllid families. Springer, Berlin.

Loconte H, DW Stevenson 1991 Cladistics of the Magnoliidae. Cladistics 7:267-296.

Maddison WP, DR Maddison 2017 Mesquite: a modular system for evolutionary analysis. Version 3.2. http://mesquiteproject.org.

Mohr BAR, MEC Bernardes-de-Oliveira 2004 Endressinia brasiliana, a Magnolialean angiosperm from the Lower Cretaceous Crato Formation (Brazil). Int I Plant Sci 165:1121-1133.

Monteillet J, J-R Lappartient 1981 Fruits et graines du Crétacé supérior des carrières de Paki (Senegal). Rev Palaeobot Palynol 34:331-344.

Rey J 1993 Les unités lithostratigraphiques du groupe de Torres Vedras (Estremadura, Portugal). Com Inst Geol Min 79:75-85.

Stampanoni M, A Groso, A Isenegger, G Mikuljan, Q Chen, A Bertrand, S Henein, et al 2006 Trends in synchrotron-based tomographic imaging: the SLS experience. In U Bonse, ed. Developments in X-Ray tomography V: proceedings of SPIE, the International Society for Optical Engineering, San Diego.

Takahashi M, EM Friis, K Uesugi, Y Suzuki, PR Crane 2008 Floral evidence of Annonaceae from the Late Cretaceous of Japan. Int I Plant Sci 169:890-898.

Takhtajan AL 1969 Flowering plants: origin and dispersal. Oliver \& Boyd, Edinburgh.

Umeda A, R Imaichi, M Kato 1994 Ovular development and morphology of the outer integument of Magnolia grandiflora (Magnoliaceae). Am I Bot 81:361-367.

Von Balthazar M, PR Crane, KR Pedersen, EM Friis 2011 New flowers of Laurales from the Early Cretaceous (Early to Middle Albian) of eastern North America. Pages 49-87 in L Wanntorp, LP Ronse De Craene eds. Flowers on the tree of life. Cambridge University Press, Cambridge.

Von Balthazar M, KR Pedersen, PR Crane, M Stampanoni, EM Friis 2007 Potomacanthus lobatus gen. et sp. nov., a new flower of probable Lauraceae from the Early Cretaceous (Early to Middle Albian) of eastern North America. Am I Bot 94:2041-2053.

Yamada T, R Imaichi, N Prakash, M Kato 2003 Developmental morphology of ovules and seeds of Austrobaileyales. Aust I Bot 51:555-564. 